Finance and Economics Discussion Series

Divisions of Research \& Statistics and Monetary Affairs

Federal Reserve Board, Washington, D.C.

\title{
Does Trading Frequency Affect Subordinated Debt Spreads?
}

\section{Christopher Bianchi, Diana Hancock, and Laura Kawano}

2005-08

NOTE: Staff working papers in the Finance and Economics Discussion Series (FEDS) are preliminary materials circulated to stimulate discussion and critical comment. The analysis and conclusions set forth are those of the authors and do not indicate concurrence by other members of the research staff or the Board of Governors. References in publications to the Finance and Economics Discussion Series (other than acknowledgement) should be cleared with the author(s) to protect the tentative character of these papers. 


\title{
Does Trading Frequency AfFect SubordinAted DeBT SPREADS?
}

\author{
Christopher Bianchi, Diana Hancock, and Laura Kawano \\ Board of Governors of the Federal Reserve System \\ Washington, DC 20551
}

December 14, 2004

\begin{abstract}
Because illiquid bonds may be relatively poorly priced, the ability to infer investor perceptions of changes in a banking organization's financial health from such bonds may be obscured. To examine the time-series effect of trading frequency on subordinated debt spreads, we consider the liquidity of subordinated debt for large, complex U.S. banking organizations over the 1987:Q2 - 2002:Q4 period. Since trade volumes are unobservable, we construct various measures of weekly trading frequency from observed bond prices. Using these indirect liquidity measures, we find evidence that trading frequency does significantly affect observed subordinated debt spreads. We also provide estimates for the premium of illiquidity.
\end{abstract}

The views expressed are those of the authors and do not necessarily reflect those of the Board of Governors of the Federal Reserve System or its staff 


\section{INTRODUCTION}

Since the mid-1980's, a growing number of observers have proposed using subordinated debt as a vehicle for improved market discipline. ${ }^{1}$ Because subordinated debt holders have an incentive to monitor a banking organization's financial condition, observed subordinated debt spreads could provide informative signals of these investors’ perceptions. However, there are several reasons why subordinated debt spreads may not accurately reflect investor perceptions of risk. $^{2}$ For example, Covitz, Hancock, and Kwast $(2004)^{3}$ demonstrate that the risk-sensitivity of bank funding manager decisions affect observed subordinated debt issuance spreads. And, Birchler and Hancock (2004) ${ }^{4}$ show that subordinated debt issuance spreads are influenced by the (less sophisticated) perceptions of senior debt investors.

In this study, we consider whether trading frequency significantly influences time-series information on large, complex, banking organization subordinated debt spreads. There are at least two reasons why this is an important topic. First, illiquid bonds, which do not trade as frequently as other bonds, may be relatively poorly priced. Consequently, it may be difficult to make inferences about investor perceptions regarding changes in a banking organization's financial condition. Second, in volatile bond markets, the uncertainty about an illiquid bond's price may be larger. But, such times may be those when supervisors may be most interested in the views of market participants.

1. See Board of Governors of the Federal Reserve System and U.S. Treasury Department, “The Feasibility and Desirability of Mandatory Subordinated Debt” Report to Congress pursuant to Section 108 of the Gramm-Leach-Bliley Act of 1999 (2002), for a summary of various subordinated debt proposals.

2. Bond characteristics (e.g., length of maturity, call options and the frequency of coupon payments), bond liquidity, and systematic risks are likely to affect secondary market spreads. Also, accurate bond prices may be difficult to obtain. See, for example, Hancock, D. and M.L. Kwast, 2001, "Using Subordinated Debt to Monitor Bank Holding Companies: Is it Feasible?,” Journal of Financial Services Research,20, pp. 147-187.

3. Covitz, D.M., D. Hancock, and M.L. Kwast, 2004, “A Reconsideration of th Risk Sensitivity of U.S. Banking Organization Subordinated Debt Spreads: A Sample Selection Approach,” Federal Reserve Bank of New York Economic Policy Review vol. 10, no. 2.

4. Birchler, U., and D. Hancock. 2004. "What Does the Yield on Subordinated Bank Debt Measure?” Board of Governors of the Federal Reserve System, Finance and Economics Discussion Series no. 2004-19. 
Using data on observed secondary market prices on the subordinated debt of large, complex U.S. banking organizations over the 1987:Q2 - 2002:Q4 period, we find that trading frequency does significantly affect subordinated debt spreads. Large gaps between observed prices for a bond significantly increases its spread. And, bonds that are traded highly frequently have significantly lower spreads than less frequently traded bonds.

\section{MEASURING TRADING FREQUENCY}

A direct measure of a bond's trading frequency would be its number or dollar volume of trades. But, the bond market is an over-the-counter market where the volume of trades for each bond is not disclosed. Instead, we use various indirect measures for weekly trading frequency for each bond that are derived from daily time-series information on Bloomberg "generic" bond prices. These prices are constructed using the consensus method, which averages observed trading prices after dropping the highest and lowest observations. A minimum of three observations is required, after dropping the highest and lowest observations, for a price to be valid, otherwise a missing value is entered for the trading price. This algorithm ensures that at least five trades occur on each date when a generic price is reported.

From this pricing series, we construct several trading frequency variables for each bond: (1) the number of weeks since the last generic bond price was reported, nweeks; (2) an indicator variable that equals one, when there has been an increase in the number of traded prices reported for adjoining weeks, upindicator; (3) a "low" trading frequency indicator variable, pricefreq", $\mathrm{g}=1,2$ and 3 , that equals one when "generic" prices are reported for only 1, 2 or 3 days in the week, and zero otherwise, and (4) a "high" trading frequency indicator variable, pricefreq", that equals one when "generic" prices are reported for all 5 days in the week, and zero otherwise.

We consider 211 bonds traded in the secondary market over the 1987:Q2 - 2002:Q4 period, which were issued by 22 large, complex, banking organizations that have been monitored monthly by U.S. bank supervisors. ${ }^{5}$ For a bond to be included in the sample, its amount

5. The U.S. banking organizations included in this study are AmSouth Bancorporation, Bank One Corporation, BankAmerica Corporation, Bank of New York Company, Citicorp, Chase Manhattan Corp., Comerica Incorporated, J.P. Morgan Chase \& Co., Firstar Corporation, First Union Corporation, FleetBoston, Huntington Bancshares Inc., Keycorp, Mellon Financial 
outstanding at issuance had to exceed $\$ 75$ million and there had to be a minimum of 20 weeks with generic prices reported by Bloomberg during the sample period.

The Appendix provides for each large, complex, banking organization a one-page summary of its subordinated notes and debenture Bloomberg generic pricing information. ${ }^{6}$ The top panel on each page contains a chart of end-of-week secondary market subordinated debt spreads over comparable maturity Treasury securities ${ }^{7}$ during the entire sample period. Solid lines in each chart appear when the weekly data are continuous. Dashed lines in each chart appear when the weekly data are discontinuous. These dashed lines are linear interpolations of spreads derived using the observed generic prices. Strikingly, these dashed lines appear well above the solid lines in cases where a banking organization has both frequently traded and infrequently traded bonds outstanding at the same time. It also appears that the dashed lines are fairly close to the solid lines when the time-series gaps are small, but are disproportionately larger as the time-series gap widens.

The bottom panel on each page contains a table with annual summary statistics on (1) the number of subordinated notes and debentures outstanding, (2) the number of such bonds with generic pricing information available from Bloomberg, (3) the number of bond-weeks with generic prices available, and (4) the number of bond-weeks with each pricing frequency, pricefreq $^{\mathrm{f}}, \mathrm{f}=1, \ldots, 5$. Looking across firms, the Bloomberg generic pricing data tend to be available for recently issued bonds, for firms with many outstanding issues, and for actively-

Corporation, PNC Financial Services Group, Inc. (but, there were no bonds issued by this organization in an amount over \$75 million), Regions Financial Corporation, Republic New York Corporation, Southtrust Corporation, SunTrust Banks, Inc., Union Planters Corporation, U.S. Bancorp, Wachovia Corporation, and Wells Fargo \& Company.

6. In the Appendix, the banking organizations are in alphabetical order.

7. Each end-of-week spread was calculated using a three-step procedure. First, yields on each bond were derived from reported bond prices using the Newton-Raphson iterative method. Second, the term structure of Treasury interest rates was identified for each date by using a smoothing spline of the forward rate curve that incorporated a "roughness" penalty determined by generalized cross validation. (The splining technique is described in Fisher, Mark, Douglas Nychka and David Zervos, 1995, "Fitting the Term Structure of Interest Rates with Smoothing Splines,” Finance and Economics Discussion Series, \#95-1, Board of Governors of the Federal Reserve System, January). Third, the spread was calculated as the difference between the derived bond yield and an interpolated Treasury yield of the same maturity. 
traded bonds. In fact, for some of the largest banking organizations (e.g., Bank of America, Citigroup, J.P. Morgan Chase \& Co.), there is a high proportion of bond-weeks with "high" trading frequency (i.e., generic prices available for every day of the week) when generic prices were available. Banking organizations with just a few bonds outstanding (e.g., Amsouth, Comerica, and Keycorp) tend to have large gaps in their time-series for Bloomberg generic price data, but these data are more likely to be available in weeks with "high" trading frequency.

\section{THE EMPIRICAL MODEL}

Various factors other than trading frequency are expected to influence observed secondary market subordinated debt spreads. For example, market leverage (i.e., the ratio of total (book) liabilities to (the market value of common stock plus the book value of preferred stock)) has been shown to be positively related to banking organization subordinated debt spreads. $^{8}$ This proxy for banking organization-specific default risk, marketlev ${ }_{i}$, evolves each day with the firm's common stock price and shifts with movements in its quarter-end balance sheet information. Because market leverage can be calculated on a weekly basis, we used this proxy for banking organization-specific risk to gauge bond market participants’ perceptions about expected default losses. ${ }^{9}$

It may also be the case that investors require a risk premium that is above and beyond the expected loss from default in order to compensate for systematic, rather than diversifiable, risk. In fact, researchers have recently identified several common risk factors in U.S. stock returns and bond spreads. ${ }^{10}$ We use three of these factors: an overall stock market excess return,

8. Higher market leverage should raise default risk. See Flannery, Mark J. and Sorin M. Sorescu, 1996, "Evidence of Bank Market Discipline in Subordinated Debenture Yields: 19831991,” Journal of Finance, 51 (4), September, pp. 1347-1377 and Hancock, Diana and Myron L. Kwast, 2001, "Using Subordinated Debt to Monitor Bank Holding Companies: Is it Feasible?,” Journal of Financial Services Research, 20:2/3, pp. 147-187.

9. Weekly market leverage data was constructed from weekly averages for the common stock price observed for each banking organization.

10. See Fama, Eugene and Kenneth R. French, 1993, "Common Risk Factors in the Returns on Stocks and Bonds,” Journal of Financial Economics, 33, February, pp. 3 -56, and Elton, Edwin J., Martin J. Gruber, Deepak Agrawal and Christopher Mann, 2000, "Explaining the Rate Spread on Corporate Bonds, The Journal of Finance, 56 (1), February, pp. 247-277. 
$E X R E T_{\mathrm{t}}$, a measure of the performance of small firms relative to large firms, $S M B_{t}$, and a measure of the performance of value stocks relative to growth stocks, $H M L_{t}{ }^{11}$

Center for Research in Security Prices (CRSP) data are used to compute a weekly average of daily excess stock returns, EXRET. The daily excess stock market returns are calculated as the difference between the daily value-weighted return on NYSE, Amex, and Nasdaq stocks and the off-the-run one-month Treasury return.

The relative performance measures, $S M B_{t}$ and $H M L_{t}$, are also calculated from CRSP data. Both of these measures depend on stratifications with respect to firm-size and with respect to book-to-market equity ratios. In each year, firms with NYSE, Amex, and Nasdaq stocks are classified as "small," when their size (price times shares) is less than the median firm size for the NYSE. And, firms are classified as "large," when their size is greater than the median firm size for the NYSE. ${ }^{12}$ In each year, firms are also stratified into three book-to-market equity groups based on the breakpoints for the bottom 30 percent, "low,” the middle 40 percent, "medium,” and the top 30 percent, "high.” The relative performance measure, $S M B_{t}$, is calculated as the difference between returns on small-firm and big-firm stock portfolios with about the same weighted-average book-to-market equity. Similarly, the relative performance measure, $H M L_{t}$, is calculated as the difference in returns on high- and low- book-to-market equity portfolios with about the same weighted-average size.

During periods of bond market stress, such as the post-Russian default period of August October 1998, sharp increases in overall corporate bond spreads over Treasuries with comparable maturities can occur. ${ }^{13}$ To proxy for bond market risk, we use an implied stock market volatility, bondvolatility, which is exogenous to, but highly correlated with, bond market volatiliy. Our volatility measure, which is computed from CRSP data, equals the weekly standard deviation of the daily S\&P 500 stock returns.

11. These three risk factors were developed in Fama, Eugene and Kenneth R. French, 1993, "Common Risk Factors in the Returns on Stocks and Bonds," Journal of Financial Economics, 33, February, pp. 3 -56.

12. June data are used for the firm size stratifications in each year of the sample.

13. Increases in overall corporate bond spreads are sometimes explained by an increase in risk aversion or by a flight to quality. 
To ascertain the effects of trading frequency on banking organization subordinated debt spreads, we use our panel data to estimate the following fixed-effects regression:

$$
\begin{aligned}
& \text { Spread }_{\text {bit }}=\alpha+\sum_{j=1}^{2} \gamma_{j} \text { marketlev }_{i, t-j}+\beta_{1} \text { EXRET }_{t}+\beta_{2} \text { SMB }_{t}+\beta_{3} H M L_{t} \\
& +\sum_{j=1}^{2} \mu_{j} \text { bondvolatility }-j+\sum_{\mathrm{j}=1}^{2} \xi_{\mathrm{j}} n w e e k s b t^{j}+\xi_{3} \text { upindicatorbt } \\
& +\xi_{4} \text { pricefreq }_{b t}^{123}+\xi_{5} \text { pricefreq } b t^{5}+\sum_{i=1}^{21} \phi_{i} \text { bankindicator }_{i}
\end{aligned}
$$

where Spread $_{b i t}$ is the secondary market spread on bond $b$ at time $t$ (issued in a previous period by banking organization $i$ ); market $l e v_{i, t}$ is the market leverage measured for banking organization $i$ at time $t ; E X R E T_{t}, S M B_{t}$, and $H M L_{t}$ are the common risk factors at time $t$; bondvolatility $_{t}$ is the proxy for bond market volatility at time $t$; nweeks ${ }_{b t}{ }^{j}$, upindicator, pricefre $_{b t}{ }^{123}$, pricefre $q_{b t}{ }^{5}$ are the trading frequency measures for bond $b$ at time $t$; and bankindicator $_{\mathrm{i}}, \mathrm{i}=1, \ldots, 22$ are the banking organization-specific indicator variables. ${ }^{14}$ Two lags for the market leverage measure of banking organization risk are included because investors may be interested in how this measure is evolving over time, rather than just its current level. ${ }^{15}$ Tests for the appropriate lag length indicated that only two lags were needed to capture such an effect. For similar reasons, two lags for the bond market volatility measure were included in the model. Because the premium contained in the spread did not appear to be a linear function of the number of weeks since the last observed generic price, we used various indicator variables constructed from nweeks $_{b t}$ of different time-interval lengths (e.g., a week, a month, a quarter, two quarters, a year, etc.).

14. One bank indicator is dropped from the regression to avoid singularity. Parameter estimates for the other bank indicators can be viewed as relative to the omitted indicator.

15. Because market leverage for week $t$ depends on the weekly average for the common stock price observed for each banking organization, the contemporaneous market leverage variable is only known at the end-of-day on the end-of-week. Understandably, the contemporaneous market leverage variable was statistically insignificant even at the 10 percent level in model specifications that included it. 


\section{FINDINGS}

Parameter estimates, t-statistics, and the $\mathrm{R}^{2}$ for the "best-fit specification" that omits the indicator variable for $n w e e k s_{b t}$ for one to 26 weeks (i.e., 1 week to 6 months) and includes indicator variables for 27 to 104 weeks and for greater than 104 weeks (i.e., 2 years) are presented in Table 1. ${ }^{16}$ As expected, the banking organization-specific default risk proxy (i.e., the lagged marketlev variables) were not only significant, but also positive. This means that an increase in default risk increased observed secondary market spreads. Moreover, an increase in bond market volatility, significantly increased observed banking organization secondary subordinated debt spreads: The parameter estimates on bondvolatility t-1 $_{1}$ and bondvolatility bo $_{t-2}$ are both positive and significant at the 5 percent level of confidence.

Not surprisingly, the common risk factors that affect aggregate corporate bond spreads and stock market returns also influenced banking organization subordinated debt spreads. Each of the common risk factors, EXRET, SMB, and $H M L$, significantly influenced observed secondary spreads on banking organization subordinated debt instruments.

Trading frequency measures importantly influenced observed secondary spreads for banking organization subordinated debt instruments. In particular, the longer the lapse between observed traded prices, measured using $n$ weeks ${ }_{b t}{ }^{j}$, the higher the secondary subordinated debt spread. Bonds that did not have generic prices available for 27 to 104 weeks had spreads that were, on average, 19 basis points higher than bonds with generic prices available more frequently. And, spreads on bonds that did not have generic prices available for two years or longer were on average 64 basis points higher than spreads on bonds that had such prices available within a six-month period. ${ }^{17}$ This is economically significant since the average spread observed for the sample period was only 101.78 basis points. Surprisingly, generic pricing

16. Indicator variables of lengths one week, two to four weeks, five to 12 weeks, and 13 to 26 weeks were individually and together insignificant at the five and ten percent level of confidence. Similarly, parameter estimates for indicators between 27 and 104 weeks were not significantly different from one another, so the more parsimonious specification is reported here.

17. Inclusion of interaction terms between the nweeks indicator variables and conteporaneous bond market volatility measures in the model suggest that the spread differential between actively- and inactively-traded bonds rises with bond market volatility. 
lapses of less than six months did not materially or significantly affect spreads. This is likely why data sources that employ matrix prices (e.g., Bloomberg Fair Value and Interactive Data Corporation) remain popular with market practitioners.

In addition, the weekly trading frequency indicator variables were statistically significant, of the expected sign, and of plausible magnitude. The "high" trading frequency indicator ( pricefreq $_{b t}{ }^{5}$ ) parameter estimate is significant and equal to -0.016 . This means that spreads on bonds that have generic prices available for each day of the week are about 1.6 basis points lower than spreads on bonds that have generic prices available less frequently during the week. The insignificant "low" trading frequency indicator $\left(\right.$ pricefreq $\left._{b t}{ }^{123}\right)$ parameter estimate means that trading four days per week does not reduce the spread that is observed when a bond trades only 1,2 or 3 days per week.

The parameter estimate on the indicator variable, upindicator, which signaled an increase in the number of generic prices reported for adjoining weeks, was not statistically significant though it was of the expected (i.e., negative) sign. This finding is consistent with the lack of a statistical difference in the spreads for bonds traded between one and four times per week. What really matters is whether a generic price is available all the time (i.e., every day during the week), or less frequently.

Banking organization-specific effects importantly influenced observed secondary spreads. The parameter estimates for the banking organization indicators are ordered in Table 1 so that the largest banking organization (measured using total consolidated assets) is first and the smallest banking organization is last. ${ }^{18}$ Larger banking organizations tend to have significantly lower spreads than smaller banking organizations. This finding is consistent with banking organization asset size importantly influencing observed secondary spreads even after the inclusion of many default risk proxies. ${ }^{19}$ Negative indicator variables for some of the regional banks (e.g., Keycorp and Mellon) are consistent with market participant views that the spreads

18. Since some of the organizations no longer exist, banking organizations are ordered by their total asset size in their last year of existence during the sample period.

19. See Flannery, Mark J. and Sorin M. Sorescu, 1996, “Evidence of Bank Market Discipline in Subordinated Debenture Yields: 1983-1991,” Journal of Finance, 51 (4), September, pp. 13471377. 
for debt issued by "known names” are lower than the spreads for debt issued by other banking organizations. ${ }^{20}$

\section{CONCLUSION}

Trading frequency measures significantly influence the observed subordinated debt spreads on instruments issued by large domestic banking organizations. When a bond does not have generic prices available for every business day during the week, its observed spreads will be about 1.5 basis points higher. When a bond has not received a generic price on Bloomberg for between 6 months and two years, it will have a spread that is about 20 basis points higher than a bond that has traded within the last six months. And, when the interval between generic prices is longer than two years, the spread will typically be 64 basis points higher than for a bond that has generic prices available within the preceding six month period. These rules-of-thumb derived from the estimated time-series model can potentially be used to adjust banking organization subordinated debt spreads calculated from observed generic prices to place frequently- and infrequently-traded bonds on a more comparable basis.

20. Board of Governors of the Federal Reserve System, 1999, "Using Subordinated Debt as an Instrument of Market Discipline,” Staff Study \#172, December, pp. 46-47. 


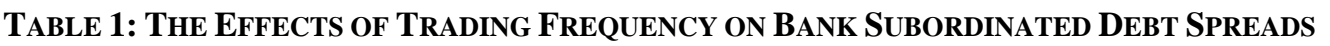

(22 Large, Complex, Banking Organizations, 206 Subordinated Instruments, Weekly Data, 1987-2002)

\begin{tabular}{|c|c|c|}
\hline DEPENDENT VARIABLES & PARAMETER ESTIMATE & T-STATISTIC \\
\hline \multicolumn{3}{|l|}{ Bank-specific Risk Measures } \\
\hline marketlev $_{\mathrm{i}, \mathrm{t}-1}$ & 0.011 & 2.67 \\
\hline marketlev $\mathrm{i}_{\mathrm{i}, \mathrm{-}-2}$ & 0.049 & 11.73 \\
\hline \multicolumn{3}{|l|}{ Common Risk Factors } \\
\hline EXRET $_{t}$ & -3.855 & -7.84 \\
\hline $\mathrm{SMB}_{\mathrm{t}}$ & 3.375 & 10.12 \\
\hline $\mathrm{HML}_{\mathrm{t}}$ & -4.000 & -9.13 \\
\hline \multicolumn{3}{|l|}{ Bond Market Volatility Measure } \\
\hline bondvolatility $_{\mathrm{t}-1}$ & 0.125 & 28.72 \\
\hline bondvolatility $_{\mathrm{t}-2}$ & 0.134 & 30.98 \\
\hline \multicolumn{3}{|l|}{ Trading Frequency Measures } \\
\hline nweeks $_{\mathrm{b}}{ }^{27,104}$ & 0.192 & 5.24 \\
\hline nweeks $_{\mathrm{b}}$ greater than 104 & 0.642 & 3.32 \\
\hline upindicator $_{\mathrm{b}, \mathrm{t}}$ & -0.005 & -0.88 \\
\hline Pricefreq $_{b, t}{ }^{123}$ & -0.001 & -0.18 \\
\hline Pricefreq $_{b, t}{ }^{5}$ & -0.016 & -2.13 \\
\hline \multicolumn{3}{|c|}{ Banking Organization-Specific Indicators } \\
\hline J.P. Morgan Chase & -0.297 & -18.89 \\
\hline Chase Manhattan & -0.158 & -10.17 \\
\hline Citicorp & -0.139 & -8.70 \\
\hline Bank of America & -0.151 & -10.04 \\
\hline Wachovia & -0.108 & -5.84 \\
\hline BancOne & -0.004 & -0.23 \\
\hline First Union & -0.197 & -11.77 \\
\hline Fleet Financial & 0.054 & 2.85 \\
\hline US Bancorp & -0.021 & -0.82 \\
\hline Suntrust & 0.266 & 5.56 \\
\hline Society (Keycorp) & -0.110 & -4.10 \\
\hline Firstar & 0.444 & 10.58 \\
\hline Bank of New York & -0.200 & -9.56 \\
\hline Comerica & 0.020 & 0.81 \\
\hline Republic NY & -0.668 & -37.15 \\
\hline Southtrust & 0.110 & 3.28 \\
\hline Regions & -0.112 & -2.30 \\
\hline Amsouth & 0.040 & 1.39 \\
\hline Mellon & -0.841 & -18.96 \\
\hline Union Planters & 0.569 & 8.57 \\
\hline Huntington & -0.242 & -6.84 \\
\hline $\begin{array}{l}\text { Goodness of Fit Measure } \\
\mathrm{R}^{2}\end{array}$ & 0.25 & \\
\hline
\end{tabular}

Note: The bank indicator variable for Wells Fargo was omitted from the regression. Remaining banking organizations are ordered by their total asset size in their last year of existence during the sample period. 


\section{APPENDIX:}

SUMMARY OF SUBORDINATED NOTES AND DEBENTURE

PRICING INFORMATION FOR LARGE, COMPLEX BANKING ORGANIZATIONS 


\section{AMSOUTH BANCORPORATION \\ $\mathrm{RSSD}=1078604$ \\ TICKER $=$ ASO}

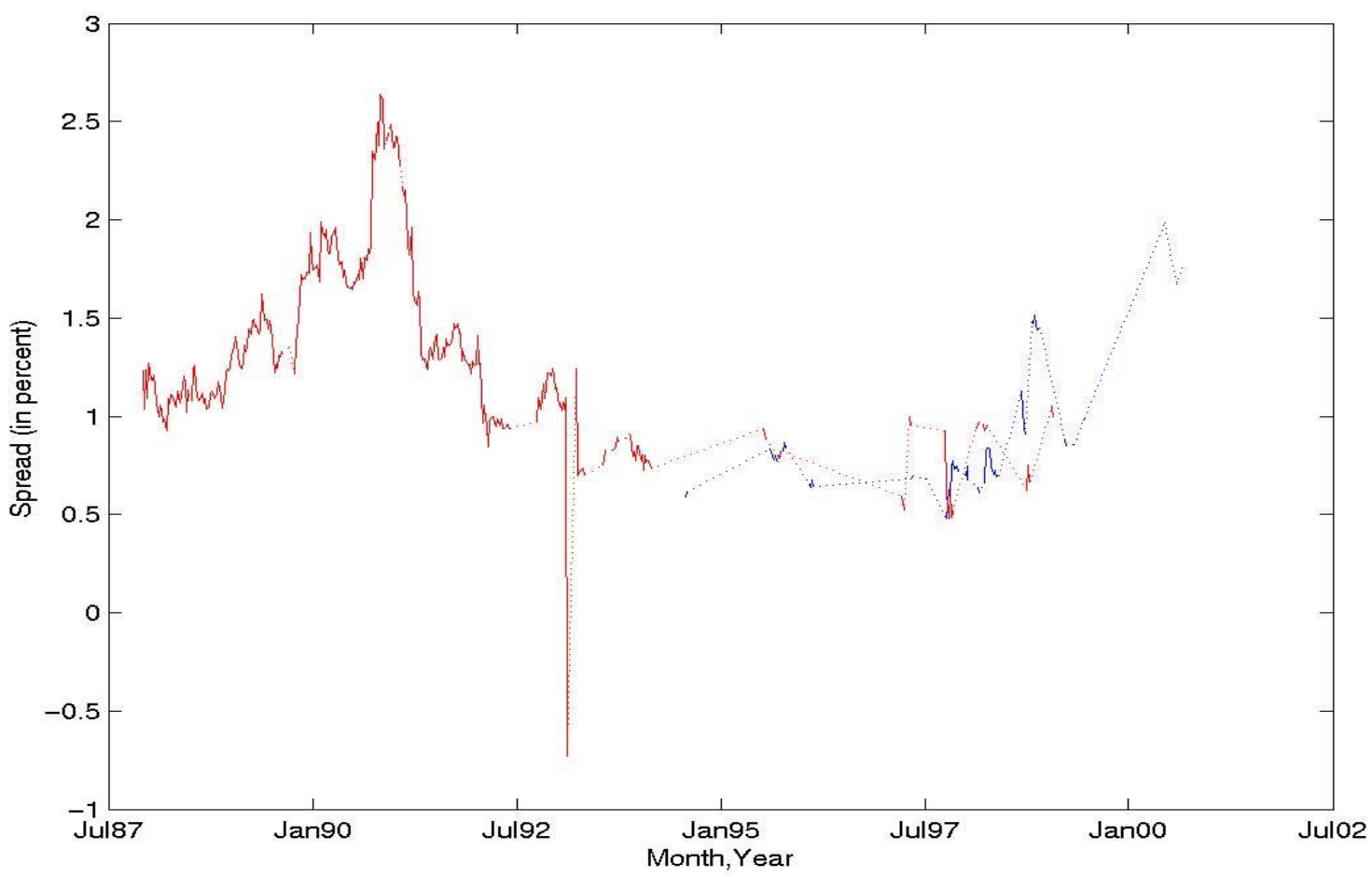

\begin{tabular}{|c|c|c|c|c|c|c|c|c|}
\hline & \multicolumn{8}{|c|}{ Year } \\
\hline & 1987 & 1988 & 1989 & 1990 & 1991 & 1992 & 1993 & 1994 \\
\hline Number of SND Outstanding & 1 & 1 & 1 & 1 & 1 & 1 & 1 & 2 \\
\hline Number of SND with Generic Pricing & 1 & 1 & 1 & 1 & 1 & 1 & 1 & 2 \\
\hline Percentage of SND with Generic Pricing & $100.00 \%$ & $100.00 \%$ & $100.00 \%$ & $100.00 \%$ & $100.00 \%$ & $100.00 \%$ & $100.00 \%$ & $100.00 \%$ \\
\hline Number of Bond-Weeks & 35 & 52 & 52 & 52 & 52 & 52 & 52 & 85 \\
\hline Number of Bond-Weeks with Generic Pricing & 5 & 51 & 47 & 50 & 51 & 37 & 30 & 10 \\
\hline Percentage of Bond-Weeks with Generic Pricing & $14.29 \%$ & $98.08 \%$ & $90.38 \%$ & $96.15 \%$ & $98.08 \%$ & $71.15 \%$ & $57.69 \%$ & $11.76 \%$ \\
\hline
\end{tabular}

Number of Bond-Weeks with Various Frequencies

\begin{tabular}{|c|c|c|c|c|c|c|c|c|}
\hline 5 & 3 & 40 & 32 & 45 & 31 & 32 & 18 & 8 \\
\hline 4 & 2 & 11 & 8 & 3 & 11 & 3 & 3 & 0 \\
\hline 3 & 0 & 0 & 2 & 0 & 4 & 0 & 4 & 0 \\
\hline 2 & 0 & 0 & 2 & 1 & 2 & 1 & 4 & 1 \\
\hline 1 & 0 & 0 & 3 & 1 & 3 & 1 & 1 & 1 \\
\hline
\end{tabular}

\begin{tabular}{|l|c|c|c|c|c|c|c|c|}
\multicolumn{1}{c|}{} & \multicolumn{9}{c|}{ Year } \\
\cline { 2 - 9 } \multicolumn{1}{c|}{} & 1995 & 1996 & 1997 & 1998 & 1999 & 2000 & 2001 & 2002 \\
\hline Number of SND Outstanding & 3 & 3 & 3 & 3 & 4 & 3 & 3 & 3 \\
\hline Pumber of SND with Generic Pricing & 2 & 1 & 2 & 2 & 2 & 1 & 0 & 0 \\
\hline
\end{tabular}

\begin{tabular}{|l|c|c|c|c|c|c|c|c|}
\hline Number of Bond-Weeks & 113 & 156 & 156 & 156 & 167 & 156 & 156 & 156 \\
\hline Number of Bond-Weeks with Generic Pricing & 14 & 4 & 24 & 36 & 8 & 5 & 0 & 0 \\
\hline Percentage of Bond-Weeks with Generic Pricing & $12.39 \%$ & $2.56 \%$ & $15.38 \%$ & $23.08 \%$ & $4.79 \%$ & $3.21 \%$ & $0.00 \%$ & $0.00 \%$ \\
\hline
\end{tabular}

Number of Bond-Weeks with Various Frequencies

\begin{tabular}{|c|c|c|c|c|c|c|c|c|}
\hline 5 & 8 & 2 & 10 & 17 & 3 & 0 & 0 & 0 \\
\hline 4 & 2 & 1 & 9 & 6 & 1 & 0 & 0 & 0 \\
\hline 3 & 1 & 1 & 3 & 3 & 0 & 3 & 0 & 0 \\
\hline 2 & 3 & 0 & 1 & 8 & 2 & 1 & 0 & 0 \\
\hline 1 & 0 & 0 & 1 & 2 & 2 & 1 & 0 & 0 \\
\hline
\end{tabular}




\section{BANC ONE CORPORATION \\ RSSD $=1068294$ \\ TICKER $=$ ONE}

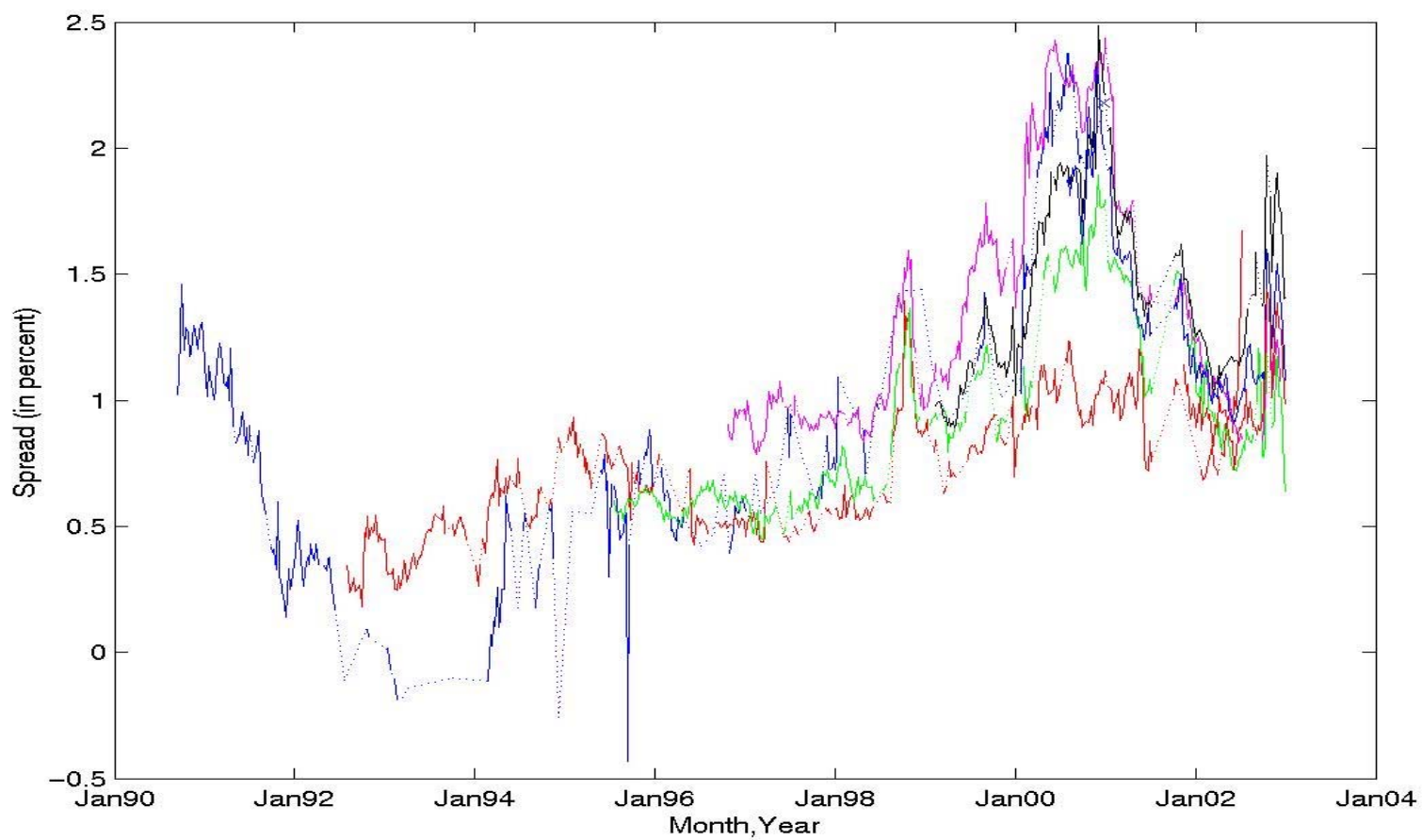

\begin{tabular}{|c|c|c|c|c|c|c|c|c|}
\hline & \multicolumn{8}{|c|}{ Year } \\
\hline & 1987 & 1988 & 1989 & 1990 & 1991 & 1992 & 1993 & 1994 \\
\hline Number of SND Outstanding & 0 & 0 & 1 & 2 & 3 & 4 & 4 & 4 \\
\hline Number of SND with Generic Pricing & 0 & 0 & 0 & 1 & 1 & 2 & 2 & 2 \\
\hline Percentage of SND with Generic Pricing & $\mathrm{N} / \mathrm{A}$ & $\mathrm{N} / \mathrm{A}$ & $0.00 \%$ & $50.00 \%$ & $33.33 \%$ & $50.00 \%$ & $50.00 \%$ & $50.00 \%$ \\
\hline
\end{tabular}

\begin{tabular}{|l|c|c|c|c|c|c|c|c|}
\hline Number of Bond-Weeks & 0 & 0 & 44 & 72 & 120 & 179 & 208 & 208 \\
\hline Number of Bond-Weeks with Generic Pricing & 0 & 0 & 0 & 16 & 48 & 49 & 54 & 63 \\
\hline Percentage of Bond-Weeks with Generic Pricing & N/A & N/A & $0.00 \%$ & $22.22 \%$ & $40.00 \%$ & $27.37 \%$ & $25.96 \%$ & $30.29 \%$ \\
\hline
\end{tabular}

Number of Bond-Weeks with Various Frequencies

\begin{tabular}{|c|c|c|c|c|c|c|c|c|}
\hline 5 & N/A & N/A & 0 & 13 & 18 & 26 & 43 & 30 \\
\hline 4 & N/A & N/A & 0 & 2 & 12 & 10 & 3 & 10 \\
\hline 3 & N/A & N/A & 0 & 0 & 4 & 7 & 2 & 5 \\
\hline 2 & N/A & N/A & 0 & 1 & 4 & 2 & 2 & 6 \\
\hline 1 & N/A & N/A & 0 & 0 & 10 & 4 & 4 & 12 \\
\hline
\end{tabular}

\begin{tabular}{|c|c|c|c|c|c|c|c|c|}
\hline & \multicolumn{8}{|c|}{ Year } \\
\hline & 1995 & 1996 & 1997 & 1998 & 1999 & 2000 & 2001 & 2002 \\
\hline Number of SND Outstanding & 6 & 7 & 9 & 9 & 10 & 11 & 12 & 13 \\
\hline Number of SND with Generic Pricing & 3 & 4 & 4 & 4 & 5 & 6 & 6 & 6 \\
\hline Percentage of SND with Generic Pricing & $50.00 \%$ & $57.14 \%$ & $44.44 \%$ & $44.44 \%$ & $50.00 \%$ & $54.55 \%$ & $50.00 \%$ & $46.15 \%$ \\
\hline
\end{tabular}

\begin{tabular}{|l|c|c|c|c|c|c|c|c|}
\hline Number of Bond-Weeks & 256 & 322 & 436 & 468 & 515 & 543 & 579 & 614 \\
\hline Number of Bond-Weeks with Generic Pricing & 95 & 121 & 146 & 153 & 173 & 253 & 187 & 268 \\
\hline Percentage of Bond-Weeks with Generic Pricing & $37.11 \%$ & $37.58 \%$ & $33.49 \%$ & $32.69 \%$ & $33.59 \%$ & $46.59 \%$ & $32.30 \%$ & $43.65 \%$ \\
\hline
\end{tabular}

Number of Bond-Weeks with Various Frequencies

\begin{tabular}{|c|c|c|c|c|c|c|c|c|}
\hline 5 & 56 & 86 & 109 & 108 & 106 & 208 & 169 & 237 \\
\hline 4 & 8 & 8 & 8 & 17 & 23 & 15 & 9 & 18 \\
\hline 3 & 5 & 10 & 15 & 11 & 17 & 11 & 6 & 1 \\
\hline 2 & 9 & 7 & 5 & 6 & 12 & 10 & 1 & 7 \\
\hline 1 & 17 & 10 & 9 & 11 & 15 & 9 & 2 & 5 \\
\hline
\end{tabular}


BANK OF AMERICA

RSSD $=1026016,1073757$

TICKER $=$ BAC

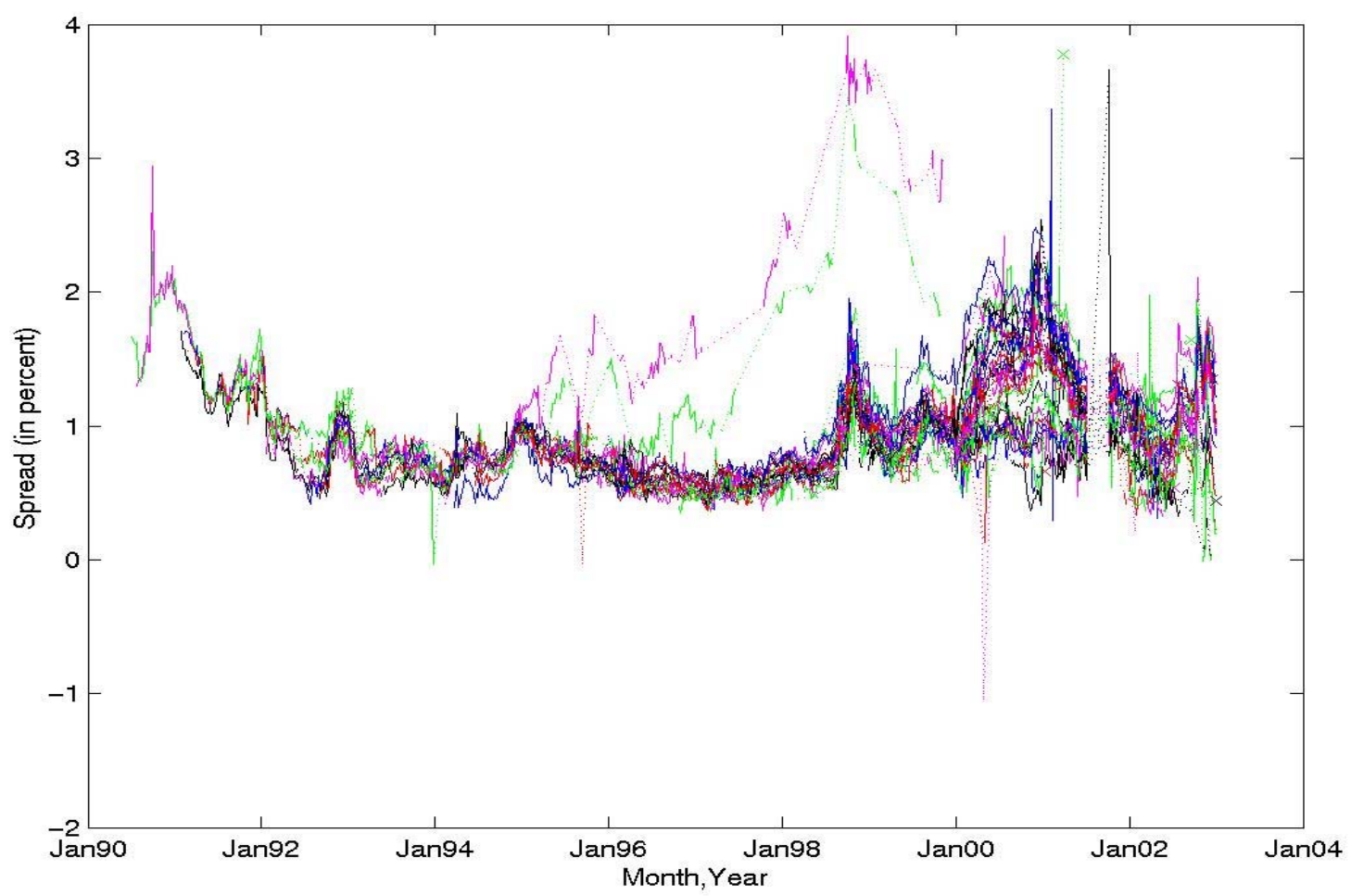

\begin{tabular}{|l|c|c|c|c|c|c|c|c|}
\multicolumn{1}{c|}{ Year } \\
\cline { 2 - 9 } \multicolumn{1}{c|}{} & 1987 & 1988 & 1989 & 1990 & 1991 & 1992 & 1993 & 1994 \\
\hline Number of SND Outstanding & 4 & 4 & 6 & 9 & 15 & 22 & 28 & 34 \\
\hline Pumber of SND with Generic Pricing & 0 & 0 & 0 & 2 & 6 & 12 & 13 & 17 \\
\hline
\end{tabular}

\begin{tabular}{|l|c|c|c|c|c|c|c|c|}
\hline Number of Bond-Weeks & 189 & 208 & 263 & 386 & 696 & 961 & 1317 & 1587 \\
\hline Number of Bond-Weeks with Generic Pricing & 0 & 0 & 0 & 49 & 273 & 404 & 560 & 626 \\
\hline Percentage of Bond-Weeks with Generic Pricing & $0.00 \%$ & $0.00 \%$ & $0.00 \%$ & $12.69 \%$ & $39.22 \%$ & $42.04 \%$ & $42.52 \%$ & $39.45 \%$ \\
\hline
\end{tabular}

Number of Bond-Weeks with Various Frequencies

\begin{tabular}{|c|c|c|c|c|c|c|c|c|}
\hline 5 & 0 & 0 & 0 & 46 & 167 & 280 & 434 & 460 \\
\hline 4 & 0 & 0 & 0 & 2 & 43 & 48 & 39 & 62 \\
\hline 3 & 0 & 0 & 0 & 0 & 31 & 35 & 31 & 48 \\
\hline 2 & 0 & 0 & 0 & 1 & 18 & 22 & 25 & 33 \\
\hline 1 & 0 & 0 & 0 & 0 & 14 & 19 & 31 & 23 \\
\hline
\end{tabular}

\begin{tabular}{|c|c|c|c|c|c|c|c|c|}
\hline & \multicolumn{8}{|c|}{ Year } \\
\hline & 1995 & 1996 & 1997 & 1998 & 1999 & 2000 & 2001 & 2002 \\
\hline Number of SND Outstanding & 38 & 45 & 46 & 47 & 47 & 46 & 52 & 49 \\
\hline Number of SND with Generic Pricing & 18 & 21 & 24 & 39 & 38 & 38 & 36 & 31 \\
\hline Percentage of SND with Generic Pricing & $47.37 \%$ & $46.67 \%$ & $52.17 \%$ & $82.98 \%$ & $80.85 \%$ & $82.61 \%$ & $69.23 \%$ & $63.27 \%$ \\
\hline Number of Bond-Weeks & 1851 & 2128 & 2304 & 2416 & 2373 & 2342 & 2390 & 2339 \\
\hline Number of Bond-Weeks with Generic Pricing & 691 & 813 & 876 & 1355 & 1345 & 1666 & 1152 & 1137 \\
\hline Percentage of Bond-Weeks with Generic Pricing & $37.33 \%$ & $38.20 \%$ & $38.02 \%$ & $56.08 \%$ & $56.68 \%$ & $71.14 \%$ & $48.20 \%$ & $48.61 \%$ \\
\hline
\end{tabular}

Number of Bond-Weeks with Various Frequencies

\begin{tabular}{|c|c|c|c|c|c|c|c|c|}
\hline 5 & 544 & 607 & 702 & 996 & 906 & 1417 & 1001 & 892 \\
\hline 4 & 52 & 79 & 48 & 132 & 191 & 80 & 39 & 65 \\
\hline 3 & 38 & 38 & 42 & 98 & 112 & 64 & 42 & 40 \\
\hline 2 & 30 & 42 & 42 & 80 & 75 & 44 & 34 & 66 \\
\hline 1 & 27 & 47 & 42 & 49 & 61 & 61 & 36 & 74 \\
\hline
\end{tabular}


BANK OF NY CO.

$\mathrm{RSSD}=1033470$

TICKER $=$ BK

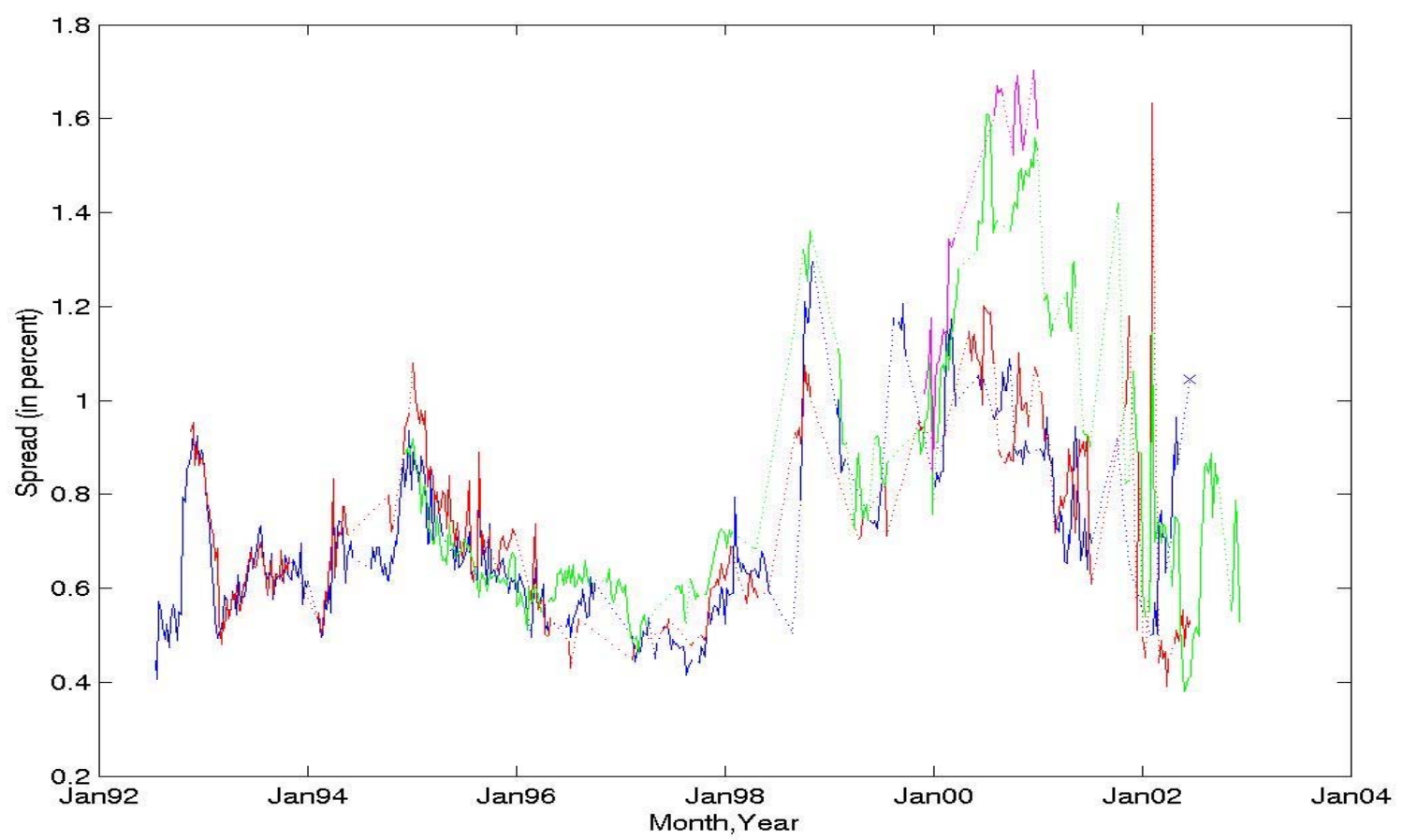

\begin{tabular}{|c|c|c|c|c|c|c|c|c|}
\hline & \multicolumn{8}{|c|}{ Year } \\
\hline & 1987 & 1988 & 1989 & 1990 & 1991 & 1992 & 1993 & 1994 \\
\hline Number of SND Outstanding & 2 & 2 & 2 & 2 & 3 & 5 & 7 & 8 \\
\hline Number of SND with Generic Pricing & 0 & 0 & 0 & 0 & 0 & 2 & 2 & 3 \\
\hline Percentage of SND with Generic Pricing & $0.00 \%$ & $0.00 \%$ & $0.00 \%$ & $0.00 \%$ & $0.00 \%$ & $40.00 \%$ & $28.57 \%$ & $37.50 \%$ \\
\hline
\end{tabular}

\begin{tabular}{|l|c|c|c|c|c|c|c|c|}
\hline Number of Bond-Weeks & 104 & 104 & 104 & 104 & 123 & 188 & 294 & 368 \\
\hline Number of Bond-Weeks with Generic Pricing & 0 & 0 & 0 & 0 & 0 & 32 & 95 & 69 \\
\hline Percentage of Bond-Weeks with Generic Pricing & $0.00 \%$ & $0.00 \%$ & $0.00 \%$ & $0.00 \%$ & $0.00 \%$ & $17.02 \%$ & $32.31 \%$ & $18.75 \%$ \\
\hline
\end{tabular}

Number of Bond-Weeks with Various Frequencies

\begin{tabular}{|c|c|c|c|c|c|c|c|c|}
\hline 5 & 0 & 0 & 0 & 0 & 0 & 29 & 88 & 55 \\
\hline 4 & 0 & 0 & 0 & 0 & 0 & 2 & 3 & 3 \\
\hline 3 & 0 & 0 & 0 & 0 & 0 & 0 & 1 & 3 \\
\hline 2 & 0 & 0 & 0 & 0 & 0 & 0 & 2 & 5 \\
\hline 1 & 0 & 0 & 0 & 0 & 0 & 1 & 1 & 3 \\
\hline
\end{tabular}

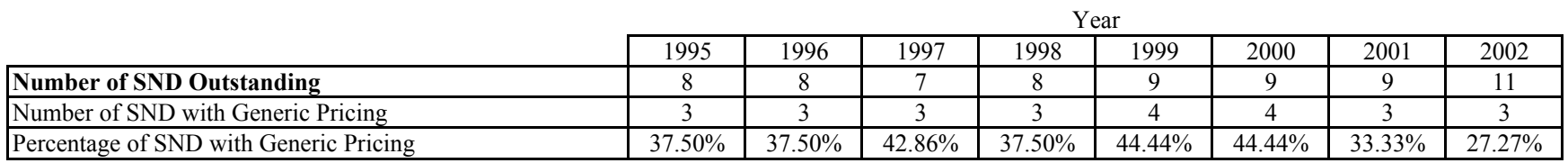

\begin{tabular}{|l|c|c|c|c|c|c|c|c|}
\hline Number of Bond-Weeks & 416 & 377 & 334 & 400 & 421 & 468 & 449 & 456 \\
\hline Number of Bond-Weeks with Generic Pricing & 149 & 90 & 94 & 69 & 61 & 128 & 84 & 78 \\
\hline Percentage of Bond-Weeks with Generic Pricing & $35.82 \%$ & $23.87 \%$ & $28.14 \%$ & $17.25 \%$ & $14.49 \%$ & $27.35 \%$ & $18.71 \%$ & $17.11 \%$ \\
\hline
\end{tabular}

Number of Bond-Weeks with Various Frequencies

\begin{tabular}{|c|c|c|c|c|c|c|c|c|}
\hline 5 & 136 & 58 & 66 & 46 & 34 & 90 & 51 & 55 \\
\hline 4 & 8 & 11 & 10 & 4 & 5 & 11 & 11 & 4 \\
\hline 3 & 0 & 8 & 4 & 6 & 12 & 8 & 3 & 2 \\
\hline 2 & 1 & 6 & 7 & 9 & 7 & 6 & 6 & 6 \\
\hline 1 & 4 & 7 & 7 & 4 & 3 & 13 & 13 & 11 \\
\hline
\end{tabular}


CHASE MANHATTAN CORPORATION

RSSD $=1039502(1040795$ prior to $3 / 31 / 1996)$

$\mathrm{TICKER}=\mathrm{CMB}$

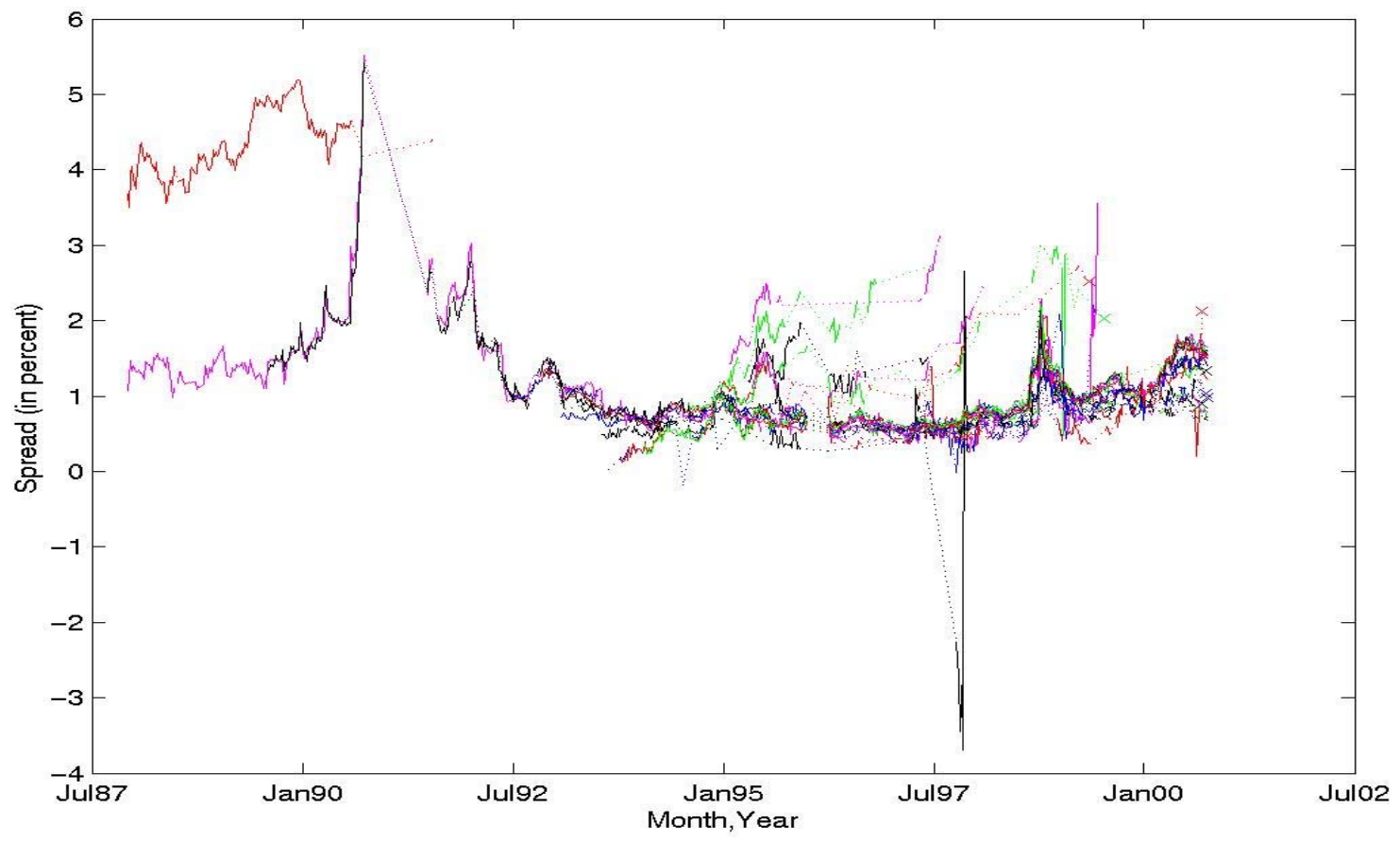

\begin{tabular}{|c|c|c|c|c|c|c|c|c|}
\hline & \multicolumn{8}{|c|}{ Year } \\
\hline & 1987 & 1988 & 1989 & 1990 & 1991 & 1992 & 1993 & 1994 \\
\hline Number of SND Outstanding & 4 & 5 & 8 & 8 & 10 & 20 & 34 & 41 \\
\hline Number of SND with Generic Pricing & 3 & 3 & 5 & 5 & 6 & 12 & 17 & 22 \\
\hline Percentage of SND with Generic Pricing & $75.00 \%$ & $60.00 \%$ & $62.50 \%$ & $62.50 \%$ & $60.00 \%$ & $60.00 \%$ & $50.00 \%$ & $53.66 \%$ \\
\hline Number of Bond-Weeks & 124 & 218 & 353 & 416 & 432 & 769 & 1437 & 2025 \\
\hline Number of Bond-Weeks with Generic Pricing & 15 & 153 & 200 & 188 & 102 & 335 & 671 & 759 \\
\hline Percentage of Bond-Weeks with Generic Pricing & $12.10 \%$ & $70.18 \%$ & $56.66 \%$ & $45.19 \%$ & $23.61 \%$ & $43.56 \%$ & $46.69 \%$ & $37.48 \%$ \\
\hline
\end{tabular}

Number of Bond-Weeks with Various Frequencies

\begin{tabular}{|c|c|c|c|c|c|c|c|c|}
\hline 5 & 9 & 120 & 178 & 174 & 22 & 198 & 571 & 577 \\
\hline 4 & 6 & 33 & 19 & 9 & 33 & 36 & 47 & 75 \\
\hline 3 & 0 & 0 & 2 & 0 & 22 & 36 & 23 & 42 \\
\hline 2 & 0 & 0 & 0 & 4 & 14 & 40 & 21 & 31 \\
\hline 1 & 0 & 0 & 1 & 1 & 11 & 25 & 9 & 34 \\
\hline
\end{tabular}

\begin{tabular}{|c|c|c|c|c|c|c|c|c|}
\hline & \multicolumn{8}{|c|}{ Year } \\
\hline & 1995 & 1996 & 1997 & 1998 & 1999 & 2000 & 2001 & 2002 \\
\hline Number of SND Outstanding & 49 & 49 & 52 & 54 & 56 & 48 & N/A & $\mathrm{N} / \mathrm{A}$ \\
\hline Number of SND with Generic Pricing & 30 & 37 & 42 & 37 & 36 & 25 & $\mathrm{~N} / \mathrm{A}$ & $\mathrm{N} / \mathrm{A}$ \\
\hline Percentage of SND with Generic Pricing & $61.22 \%$ & $75.51 \%$ & $80.77 \%$ & $68.52 \%$ & $64.29 \%$ & $52.08 \%$ & $\mathrm{~N} / \mathrm{A}$ & $\mathrm{N} / \mathrm{A}$ \\
\hline
\end{tabular}

\begin{tabular}{|l|c|c|c|c|c|c|c|c|}
\hline Number of Bond-Weeks & 2466 & 2547 & 2653 & 2737 & 2685 & 2397 & N/A & N/A \\
\hline Number of Bond-Weeks with Generic Pricing & 1029 & 649 & 1065 & 1041 & 932 & 646 & N/A & N/A \\
\hline Percentage of Bond-Weeks with Generic Pricing & $41.73 \%$ & $25.48 \%$ & $40.14 \%$ & $38.03 \%$ & $34.71 \%$ & $26.95 \%$ & N/A & N/A \\
\hline
\end{tabular}

\section{Number of Bond-Weeks with Various Frequencies}

\begin{tabular}{|c|c|c|c|c|c|c|c|c|}
\hline 5 & 776 & 421 & 728 & 700 & 643 & 467 & N/A & N/A \\
\hline 4 & 82 & 72 & 97 & 127 & 116 & 55 & N/A & N/A \\
\hline 3 & 48 & 49 & 98 & 93 & 75 & 37 & N/A & N/A \\
\hline 2 & 60 & 57 & 65 & 59 & 52 & 39 & N/A & N/A \\
\hline 1 & 63 & 50 & 77 & 62 & 46 & 48 & N/A & N/A \\
\hline
\end{tabular}

** Chase Manhattan Corporation merged into J.P. Morgan Chase \& Co. on 12/31/2000 


\section{CITICORP}

$\mathrm{RSSD}=1951350,1042351$

$\mathrm{TICKER}=\mathrm{C}, \mathrm{CCI}$

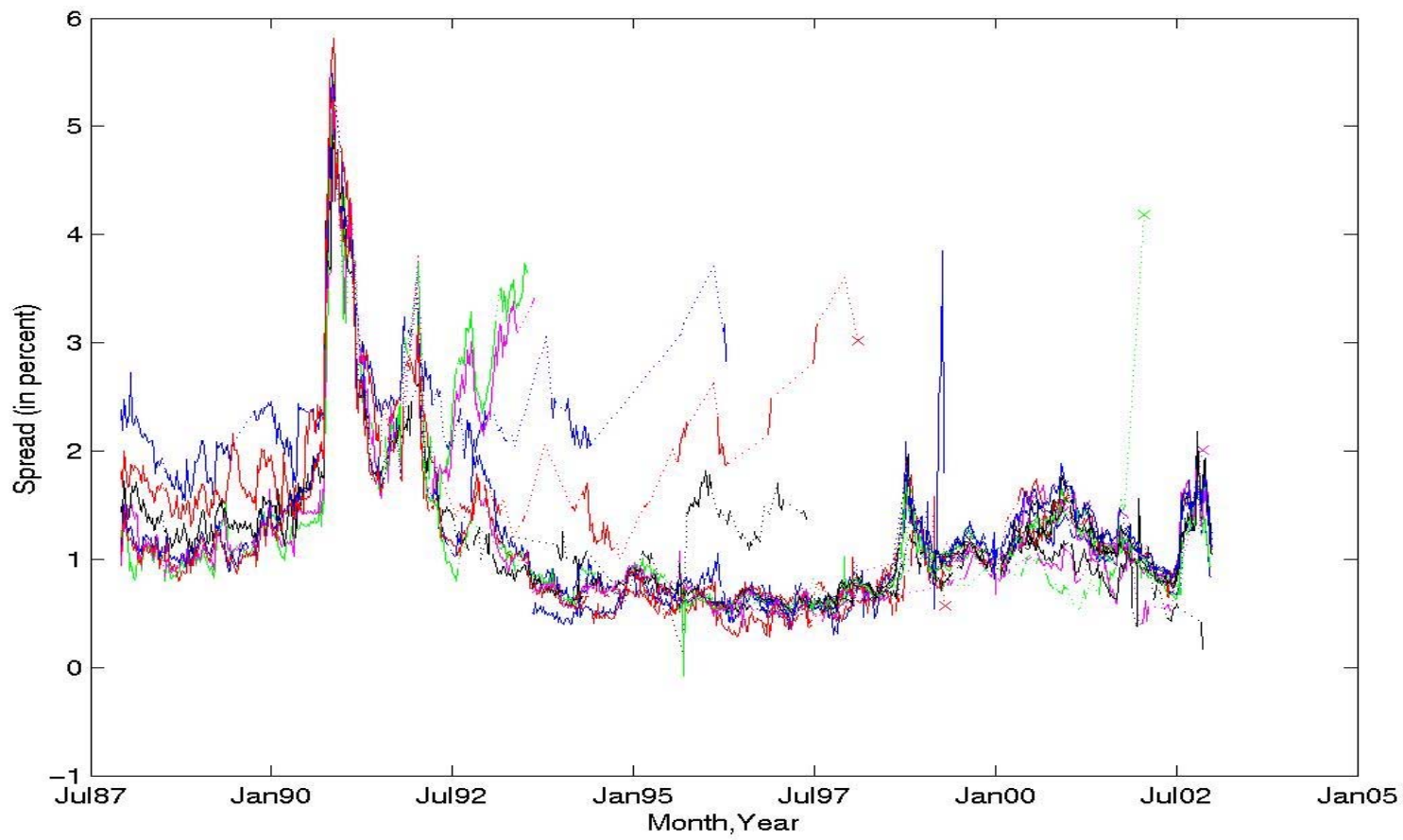

\begin{tabular}{|c|c|c|c|c|c|c|c|c|}
\hline & \multicolumn{8}{|c|}{ Year } \\
\hline & 1987 & 1988 & 1989 & 1990 & 1991 & 1992 & 1993 & 1994 \\
\hline Number of SND Outstanding & 11 & 11 & 11 & 11 & 11 & 13 & 15 & 18 \\
\hline Number of SND with Generic Pricing & 7 & 7 & 7 & 7 & 7 & 9 & 11 & 10 \\
\hline Percentage of SND with Generic Pricing & $63.64 \%$ & $63.64 \%$ & $63.64 \%$ & $63.64 \%$ & $63.64 \%$ & $69.23 \%$ & $73.33 \%$ & $55.56 \%$ \\
\hline
\end{tabular}

\begin{tabular}{|l|c|c|c|c|c|c|c|c|}
\hline Number of Bond-Weeks & 525 & 572 & 572 & 572 & 572 & 622 & 739 & 892 \\
\hline Number of Bond-Weeks with Generic Pricing & 35 & 357 & 343 & 352 & 273 & 329 & 344 & 358 \\
\hline Percentage of Bond-Weeks with Generic Pricing & $6.67 \%$ & $62.41 \%$ & $59.97 \%$ & $61.54 \%$ & $47.73 \%$ & $52.89 \%$ & $46.55 \%$ & $40.13 \%$ \\
\hline
\end{tabular}

Number of Bond-Weeks with Various Frequencies

\begin{tabular}{|c|c|c|c|c|c|c|c|c|}
\hline 5 & 21 & 280 & 295 & 314 & 112 & 187 & 257 & 258 \\
\hline 4 & 14 & 77 & 40 & 26 & 39 & 42 & 24 & 30 \\
\hline 3 & 0 & 0 & 2 & 3 & 47 & 42 & 20 & 26 \\
\hline 2 & 0 & 0 & 2 & 4 & 38 & 27 & 21 & 26 \\
\hline 1 & 0 & 0 & 4 & 5 & 37 & 31 & 22 & 18 \\
\hline
\end{tabular}

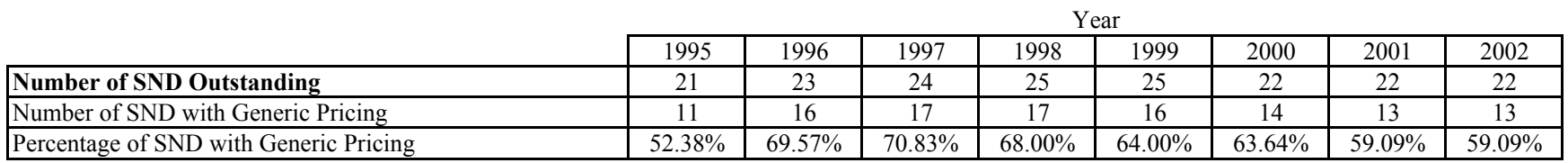

\begin{tabular}{|l|c|c|c|c|c|c|c|c|}
\hline Number of Bond-Weeks & 955 & 1084 & 1153 & 1232 & 1208 & 1144 & 1144 & 1094 \\
\hline Number of Bond-Weeks with Generic Pricing & 392 & 523 & 556 & 493 & 453 & 591 & 575 & 507 \\
\hline Percentage of Bond-Weeks with Generic Pricing & $41.05 \%$ & $48.25 \%$ & $48.22 \%$ & $40.02 \%$ & $37.50 \%$ & $51.66 \%$ & $50.26 \%$ & $46.34 \%$ \\
\hline
\end{tabular}

Number of Bond-Weeks with Various Frequencies

\begin{tabular}{|c|c|c|c|c|c|c|c|c|}
\hline 5 & 313 & 416 & 425 & 340 & 306 & 459 & 501 & 408 \\
\hline 4 & 26 & 44 & 33 & 43 & 71 & 39 & 23 & 30 \\
\hline 3 & 18 & 19 & 36 & 41 & 35 & 33 & 13 & 19 \\
\hline 2 & 16 & 21 & 35 & 34 & 21 & 18 & 15 & 27 \\
\hline 1 & 19 & 23 & 27 & 35 & 20 & 42 & 23 & 23 \\
\hline
\end{tabular}


COMERICA

$\mathrm{RSSD}=1199844$

TICKER $=$ CMA

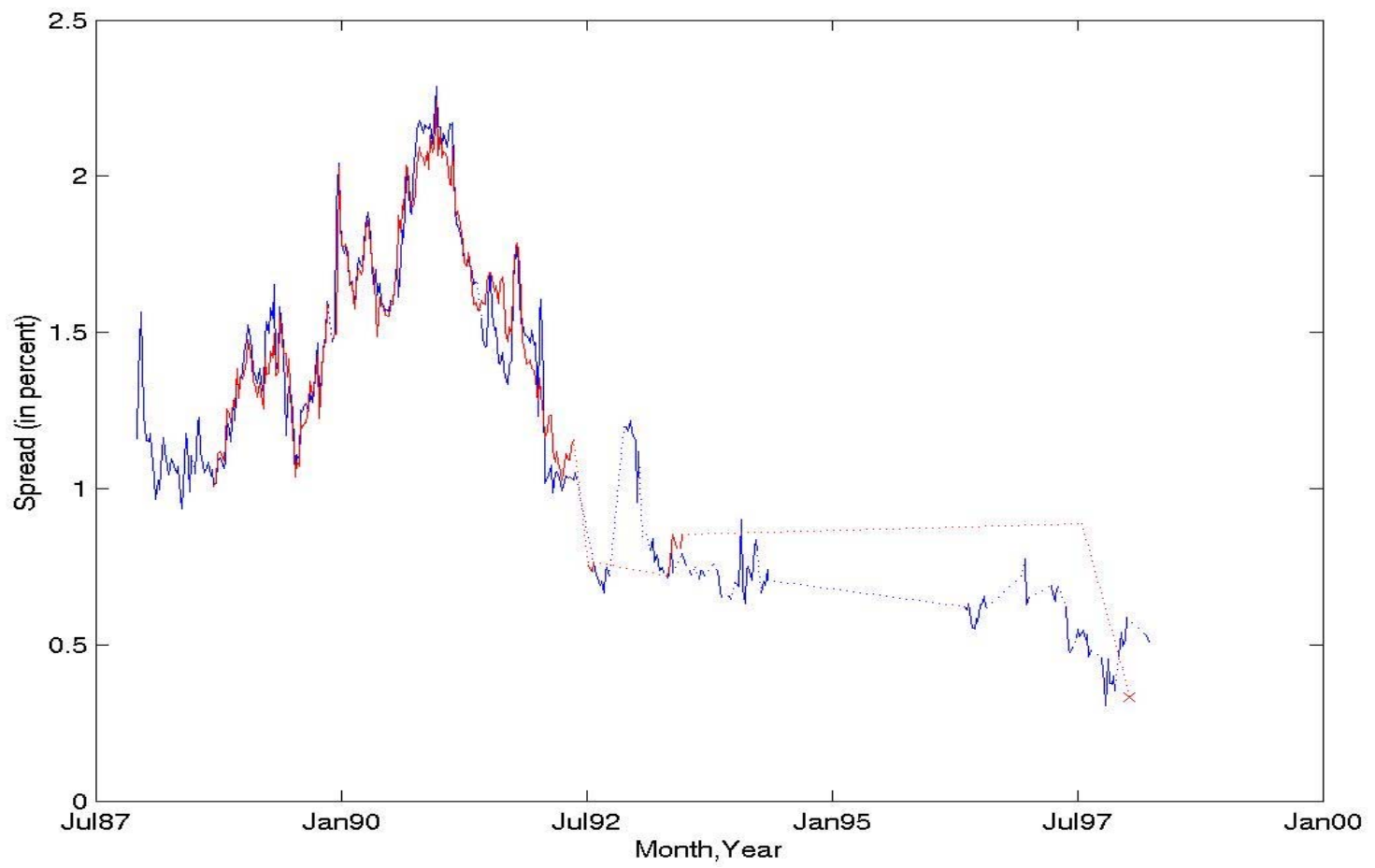

\begin{tabular}{|c|c|c|c|c|c|c|c|c|}
\hline & \multicolumn{8}{|c|}{ Year } \\
\hline & 1987 & 1988 & 1989 & 1990 & 1991 & 1992 & 1993 & 1994 \\
\hline Number of SND Outstanding & 1 & 2 & 2 & 2 & 2 & 2 & 2 & 2 \\
\hline Number of SND with Generic Pricing & 1 & 2 & 2 & 2 & 2 & 2 & 2 & 1 \\
\hline Percentage of SND with Generic Pricing & $100.00 \%$ & $100.00 \%$ & $100.00 \%$ & $100.00 \%$ & $100.00 \%$ & $100.00 \%$ & $100.00 \%$ & $50.00 \%$ \\
\hline Number of Bond-Weeks & 34 & 85 & 104 & 104 & 104 & 104 & 104 & 104 \\
\hline Number of Bond-Weeks with Generic Pricing & 5 & 67 & 102 & 104 & 103 & 62 & 40 & 18 \\
\hline Percentage of Bond-Weeks with Generic Pricing & $14.71 \%$ & $78.82 \%$ & $98.08 \%$ & $100.00 \%$ & $99.04 \%$ & $59.62 \%$ & $38.46 \%$ & $17.31 \%$ \\
\hline
\end{tabular}

Number of Bond-Weeks with Various Frequencies

\begin{tabular}{|c|c|c|c|c|c|c|c|c|}
\hline 5 & 3 & 50 & 88 & 100 & 67 & 46 & 10 & 15 \\
\hline 4 & 2 & 17 & 10 & 4 & 11 & 8 & 4 & 2 \\
\hline 3 & 0 & 0 & 0 & 0 & 14 & 4 & 15 & 0 \\
\hline 2 & 0 & 0 & 2 & 0 & 4 & 1 & 7 & 1 \\
\hline 1 & 0 & 0 & 2 & 0 & 7 & 3 & 4 & 0 \\
\hline
\end{tabular}

\begin{tabular}{|l|c|c|c|c|c|c|c|c|}
\multicolumn{1}{c|}{ Year } \\
\cline { 2 - 9 } \multicolumn{1}{c|}{} & 1995 & 1996 & 1997 & 1998 & 1999 & 2000 & 2001 & 2002 \\
\hline Number of SND Outstanding & 3 & 3 & 3 & 3 & 2 & 1 & 1 & 1 \\
\hline Pumber of SND with Generic Pricing & 0 & 1 & 2 & 2 & 0 & 0 & 0 & 0 \\
\hline
\end{tabular}

\begin{tabular}{|l|c|c|c|c|c|c|c|c|}
\hline Number of Bond-Weeks & 126 & 156 & 156 & 127 & 70 & 52 & 52 & 52 \\
\hline Number of Bond-Weeks with Generic Pricing & 0 & 16 & 33 & 5 & 0 & 0 & 0 & 0 \\
\hline Percentage of Bond-Weeks with Generic Pricing & $0.00 \%$ & $10.26 \%$ & $21.15 \%$ & $3.94 \%$ & $0.00 \%$ & $0.00 \%$ & $0.00 \%$ & $0.00 \%$ \\
\hline
\end{tabular}

Number of Bond-Weeks with Various Frequencies

\begin{tabular}{|c|c|c|c|c|c|c|c|c|}
\hline 5 & 0 & 14 & 21 & 2 & 0 & 0 & 0 & 0 \\
\hline 4 & 0 & 0 & 1 & 0 & 0 & 0 & 0 & 0 \\
\hline 3 & 0 & 1 & 3 & 0 & 0 & 0 & 0 & 0 \\
\hline 2 & 0 & 0 & 5 & 2 & 0 & 0 & 0 & 0 \\
\hline 1 & 0 & 1 & 3 & 1 & 0 & 0 & 0 & 0 \\
\hline
\end{tabular}


FIRST UNION

RSSD $=1073551$

TICKER $=$ FTU

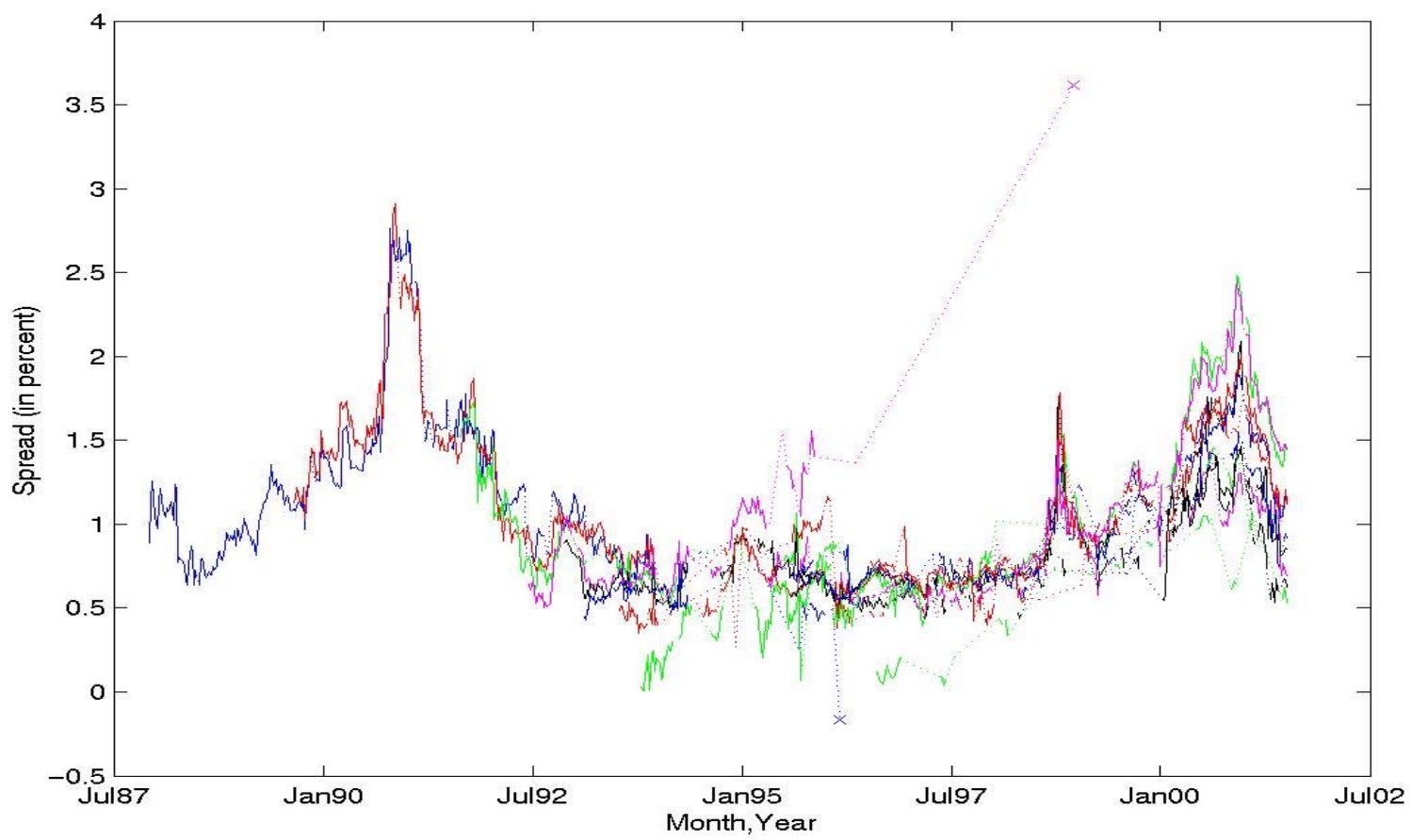

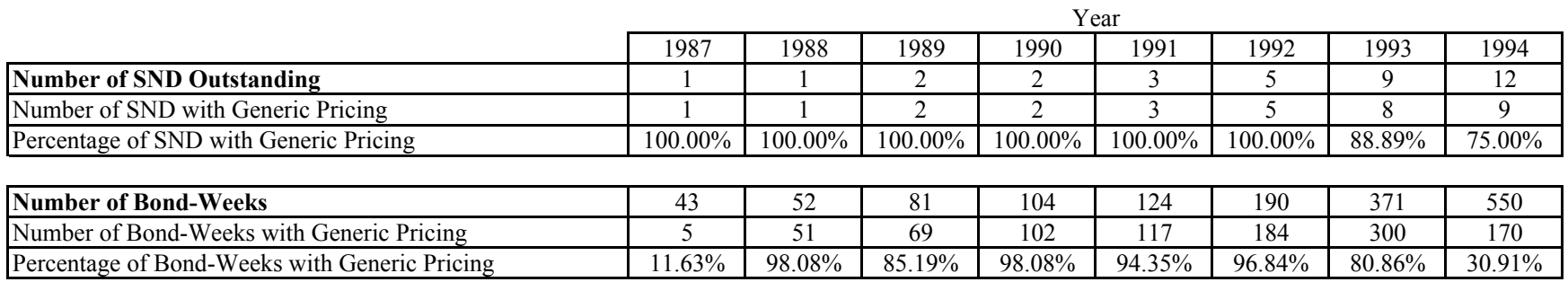

Number of Bond-Weeks with Various Frequencies

\begin{tabular}{|c|c|c|c|c|c|c|c|c|}
\hline 5 & 3 & 40 & 57 & 92 & 68 & 137 & 256 & 108 \\
\hline 4 & 2 & 11 & 6 & 8 & 20 & 20 & 23 & 18 \\
\hline 3 & 0 & 0 & 3 & 0 & 13 & 11 & 12 & 13 \\
\hline 2 & 0 & 0 & 2 & 2 & 9 & 11 & 4 & 19 \\
\hline 1 & 0 & 0 & 1 & 0 & 7 & 5 & 5 & 12 \\
\hline
\end{tabular}

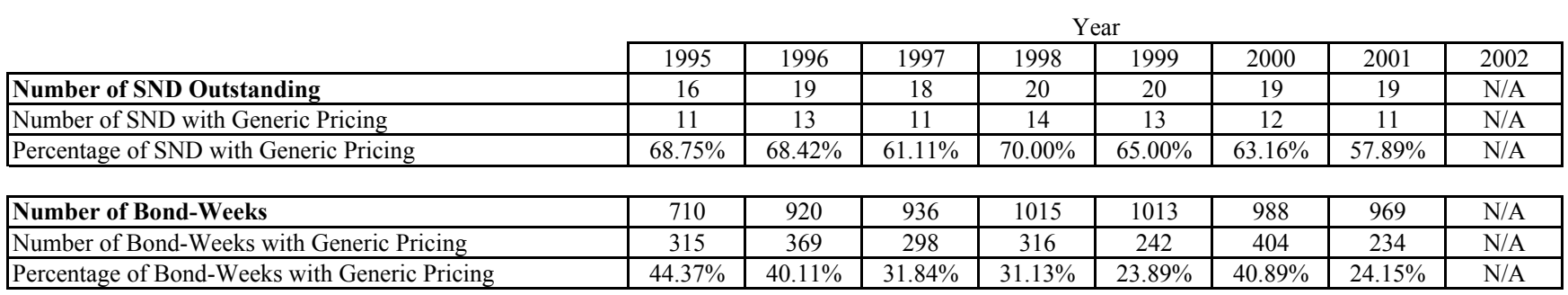

\section{Number of Bond-Weeks with Various Frequencies}

\begin{tabular}{|c|c|c|c|c|c|c|c|c|}
\hline 5 & 235 & 289 & 201 & 206 & 151 & 302 & 204 & N/A \\
\hline 4 & 22 & 34 & 30 & 27 & 29 & 36 & 7 & N/A \\
\hline 3 & 17 & 16 & 29 & 31 & 25 & 22 & 10 & N/A \\
\hline 2 & 19 & 12 & 20 & 30 & 18 & 18 & 3 & N/A \\
\hline 1 & 22 & 18 & 18 & 22 & 19 & 26 & 10 & N/A \\
\hline
\end{tabular}

\footnotetext{
*** Acquired by Wachovia on $9 / 1 / 2001$
} 
FIRSTAR CORP

RSSD $=1199479$ (1123960 prior to 6/30/1989; currently owned by US Bancorp)

TICKER $=$ FSR

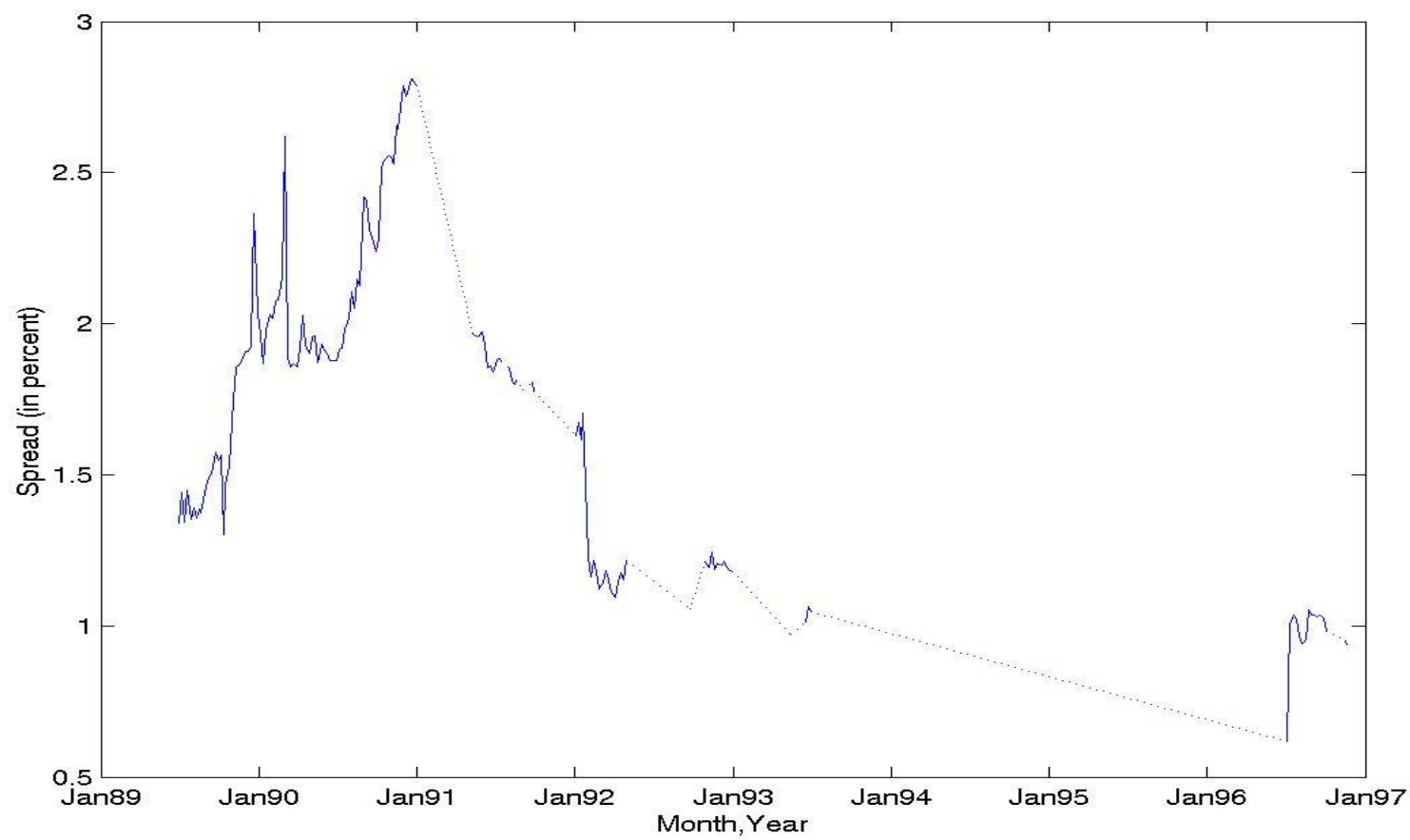

\begin{tabular}{l}
\multicolumn{1}{c|}{ Year } \\
\begin{tabular}{|l|c|c|c|c|c|c|c|c|}
\hline Number of SND Outstanding & 1987 & 1988 & 1989 & 1990 & 1991 & 1992 & 1993 & 1994 \\
\hline Number of SND with Generic Pricing & 0 & 1 & 1 & 1 & 1 & 1 & 1 & 1 \\
\hline Percentage of SND with Generic Pricing & 0 & 0 & 1 & 1 & 1 & 1 & 1 & 0 \\
\hline Number of Bond-Weeks & N/A & $0.00 \%$ & $100.00 \%$ & $100.00 \%$ & $100.00 \%$ & $100.00 \%$ & $100.00 \%$ & $0.00 \%$ \\
\hline Number of Bond-Weeks with Generic Pricing & 0 & 35 & 52 & 52 & 52 & 52 & 52 & 52 \\
\hline Percentage of Bond-Weeks with Generic Pricing & 0 & 0 & 27 & 52 & 19 & 29 & 4 & 0 \\
\hline
\end{tabular} \\
\hline
\end{tabular}

Number of Bond-Weeks with Various Frequencies

\begin{tabular}{|c|c|c|c|c|c|c|c|c|}
\hline 5 & N/A & N/A & 20 & 46 & 7 & 20 & 1 & N/A \\
\hline 4 & N/A & N/A & 3 & 3 & 4 & 3 & 1 & N/A \\
\hline 3 & N/A & N/A & 1 & 1 & 2 & 3 & 0 & N/A \\
\hline 2 & N/A & N/A & 2 & 0 & 3 & 1 & 1 & N/A \\
\hline 1 & N/A & N/A & 1 & 2 & 3 & 2 & 1 & N/A \\
\hline
\end{tabular}

\begin{tabular}{|c|c|c|c|c|c|c|c|c|}
\hline & & & & & & & & \\
\hline & 1995 & 1996 & 1997 & 1998 & 1999 & 2000 & 2001 & 2002 \\
\hline Number of SND Outstanding & 2 & 2 & 2 & 2 & $\mathrm{~N} / \mathrm{A}$ & $\mathrm{N} / \mathrm{A}$ & $\mathrm{N} / \mathrm{A}$ & $\mathrm{N} / \mathrm{A}$ \\
\hline Number of SND with Generic Pricing & 0 & 1 & 0 & 0 & $\mathrm{~N} / \mathrm{A}$ & $\mathrm{N} / \mathrm{A}$ & $\mathrm{N} / \mathrm{A}$ & $\mathrm{N} / \mathrm{A}$ \\
\hline Percentage of SND with Generic Pricing & $0.00 \%$ & $50.00 \%$ & $0.00 \%$ & $0.00 \%$ & $\mathrm{~N} / \mathrm{A}$ & $\mathrm{N} / \mathrm{A}$ & $\mathrm{N} / \mathrm{A}$ & $\mathrm{N} / \mathrm{A}$ \\
\hline Number of Bond-Weeks & 71 & 104 & 104 & 70 & $\mathrm{~N} / \mathrm{A}$ & $\mathrm{N} / \mathrm{A}$ & $\mathrm{N} / \mathrm{A}$ & $\mathrm{N} / \mathrm{A}$ \\
\hline Number of Bond-Weeks with Generic Pricing & 0 & 16 & 0 & 0 & N/A & N/A & $\mathrm{N} / \mathrm{A}$ & N/A \\
\hline Percentage of Bond-Weeks with Generic Pricing & $0.00 \%$ & $15.38 \%$ & $0.00 \%$ & $0.00 \%$ & N/A & $\mathrm{N} / \mathrm{A}$ & $\mathrm{N} / \mathrm{A}$ & $\mathrm{N} / \mathrm{A}$ \\
\hline
\end{tabular}

\section{Number of Bond-Weeks with Various Frequencies}

\begin{tabular}{|c|c|c|c|c|c|c|c|c|}
\hline 5 & N/A & 10 & N/A & N/A & N/A & N/A & N/A & $\mathrm{N} / \mathrm{A}$ \\
\hline$\overline{4}$ & N/A & 2 & N/A & N/A & N/A & $\mathrm{N} / \mathrm{A}$ & N/A & $\mathrm{N} / \mathrm{A}$ \\
\hline 3 & N/A & 2 & N/A & N/A & N/A & N/A & N/A & $\mathrm{N} / \mathrm{A}$ \\
\hline 2 & N/A & 2 & N/A & N/A & N/A & N/A & N/A & N/A \\
\hline 1 & N/A & 0 & N/A & N/A & N/A & N/A & N/A & N/A \\
\hline
\end{tabular}

*** Acquired by US Bancorp on 12/31/1998 


\section{FLEETBOSTON FINANCIAL CORP}

$\mathrm{RSSD}=1113514$

TICKER $=$ FBF $($ FLT, FNG)

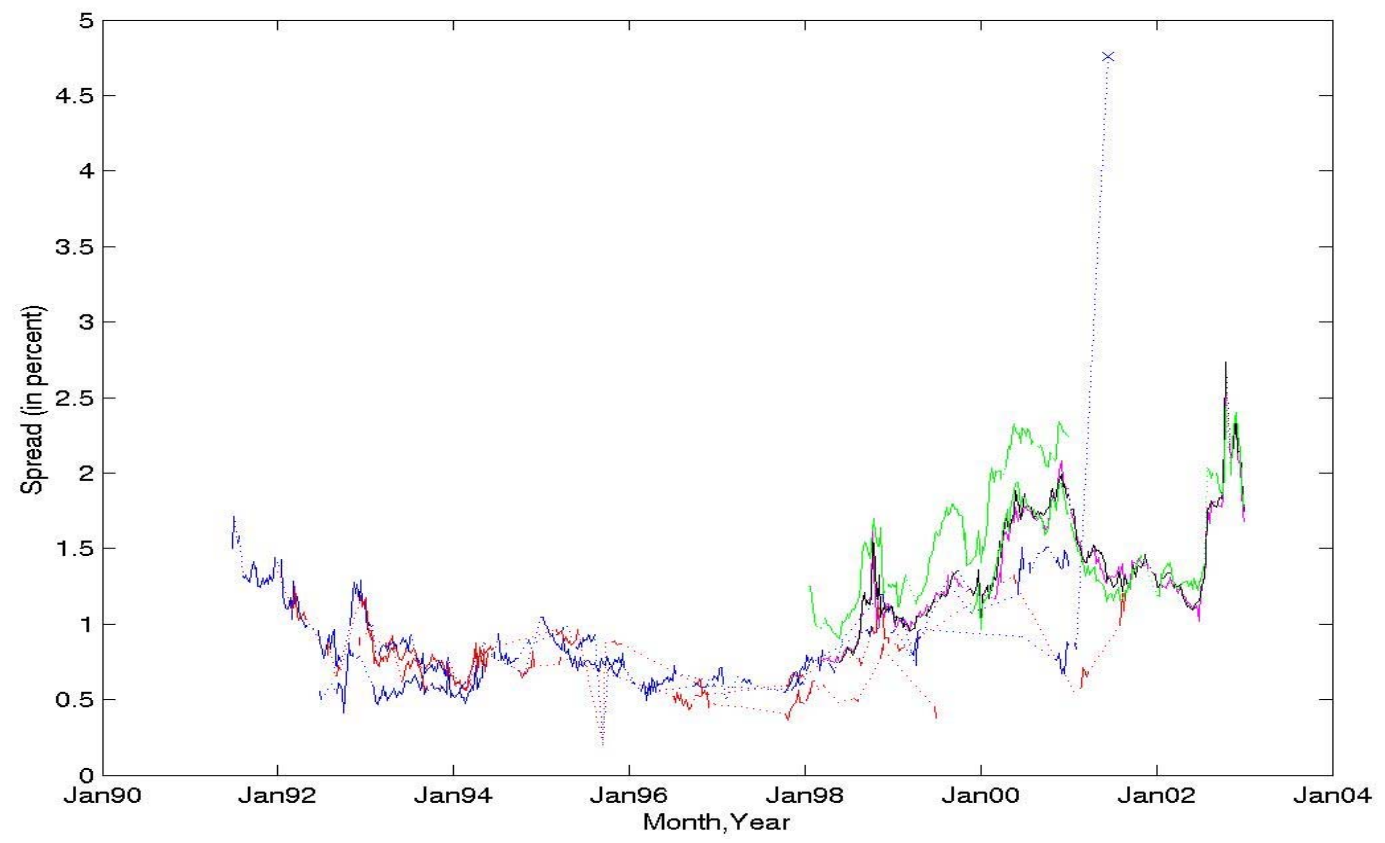

\begin{tabular}{|l|c|c|c|c|c|c|c|c|}
\multicolumn{1}{c|}{} & \multicolumn{9}{c|}{ Year } \\
\cline { 2 - 9 } Number of SND Outstanding & 1987 & 1988 & 1989 & 1990 & 1991 & 1992 & 1993 & 1994 \\
\hline Number of SND with Generic Pricing & 0 & 0 & 0 & 0 & 2 & 5 & 6 & 6 \\
\hline Percentage of SND with Generic Pricing & 0 & 0 & 0 & 0 & 2 & 4 & 4 & 4 \\
\hline
\end{tabular}

Number of Bond-Weeks

Number of Bond-Weeks with Generic Pricing

Percentage of Bond-Weeks with Generic Pricing

\begin{tabular}{|c|c|c|c|c|c|c|c|}
\hline 0 & 0 & 0 & 0 & 33 & 186 & 305 & 312 \\
\hline 0 & 0 & 0 & 0 & 25 & 80 & 169 & 92 \\
\hline N/A & N/A & N/A & N/A & $75.76 \%$ & $43.01 \%$ & $55.41 \%$ & $29.49 \%$ \\
\hline
\end{tabular}

Number of Bond-Weeks with Various Frequencies

\begin{tabular}{|c|c|c|c|c|c|c|c|c|}
\hline 5 & N/A & N/A & N/A & N/A & 7 & 39 & 136 & 67 \\
\hline 4 & N/A & N/A & N/A & N/A & 5 & 13 & 16 & 5 \\
\hline 3 & N/A & N/A & N/A & N/A & 5 & 7 & 8 & 6 \\
\hline 2 & N/A & N/A & N/A & N/A & 5 & 14 & 4 & 8 \\
\hline 1 & N/A & N/A & N/A & N/A & 3 & 7 & 5 & 6 \\
\hline
\end{tabular}

\begin{tabular}{|l|c|c|c|c|c|c|c|c|c|}
\multicolumn{1}{c|}{} & \multicolumn{9}{c|}{ Year } \\
\cline { 2 - 10 } \multicolumn{1}{c|}{ Number of SND Outstanding } & 1995 & 1996 & 1997 & 1998 & 1999 & 2000 & 2001 & 2002 \\
\hline Number of SND with Generic Pricing & 6 & 7 & 7 & 12 & 13 & 12 & 12 & 10 \\
\hline Percentage of SND with Generic Pricing & 4 & 4 & 4 & 7 & 8 & 7 & 5 & 3 \\
\hline
\end{tabular}

\begin{tabular}{|l|c|c|c|c|c|c|c|c|}
\hline Number of Bond-Weeks & 312 & 350 & 364 & 551 & 626 & 624 & 592 & 520 \\
\hline Number of Bond-Weeks with Generic Pricing & 100 & 74 & 58 & 183 & 162 & 230 & 153 & 150 \\
\hline Percentage of Bond-Weeks with Generic Pricing & $32.05 \%$ & $21.14 \%$ & $15.93 \%$ & $33.21 \%$ & $25.88 \%$ & $36.86 \%$ & $25.84 \%$ & $28.85 \%$ \\
\hline
\end{tabular}

Number of Bond-Weeks with Various Frequencies

\begin{tabular}{|c|c|c|c|c|c|c|c|c|}
\hline 5 & 82 & 44 & 38 & 138 & 118 & 197 & 135 & 121 \\
\hline 4 & 4 & 12 & 9 & 14 & 23 & 13 & 5 & 11 \\
\hline 3 & 2 & 11 & 4 & 11 & 6 & 11 & 4 & 6 \\
\hline 2 & 7 & 4 & 3 & 11 & 9 & 4 & 5 & 6 \\
\hline 1 & 5 & 3 & 4 & 9 & 6 & 5 & 4 & 6 \\
\hline
\end{tabular}




\section{HUNTINGTON BANCSHARES \\ $\mathrm{RSSD}=1068191$ \\ TICKER $=$ HBAN}

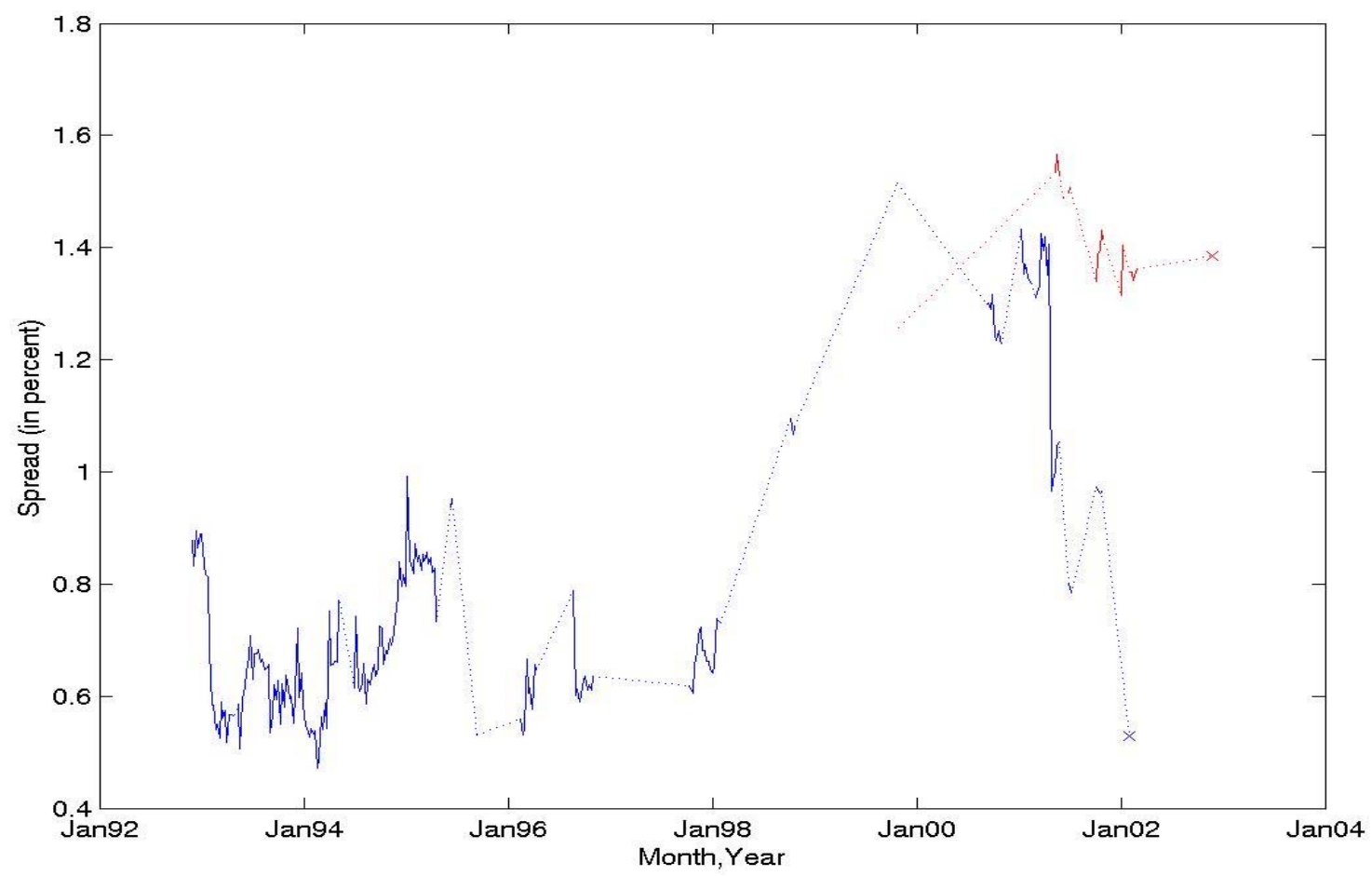

\begin{tabular}{|c|c|c|c|c|c|c|c|c|}
\hline & \multicolumn{8}{|c|}{ Year } \\
\hline & 1987 & 1988 & 1989 & 1990 & 1991 & 1992 & 1993 & 1994 \\
\hline Number of SND Outstanding & 0 & 0 & 0 & 0 & 0 & 1 & 1 & 1 \\
\hline Number of SND with Generic Pricing & 0 & 0 & 0 & 0 & 0 & 1 & 1 & 1 \\
\hline Percentage of SND with Generic Pricing & $\mathrm{N} / \mathrm{A}$ & N/A & $\mathrm{N} / \mathrm{A}$ & $\mathrm{N} / \mathrm{A}$ & $\mathrm{N} / \mathrm{A}$ & $100.00 \%$ & $100.00 \%$ & $100.00 \%$ \\
\hline Number of Bond-Weeks & 0 & 0 & 0 & 0 & 0 & 6 & 52 & 52 \\
\hline Number of Bond-Weeks with Generic Pricing & 0 & 0 & 0 & 0 & 0 & 6 & 51 & 46 \\
\hline Percentage of Bond-Weeks with Generic Pricing & N/A & N/A & N/A & N/A & N/A & $100.00 \%$ & $98.08 \%$ & $88.46 \%$ \\
\hline
\end{tabular}

Number of Bond-Weeks with Various Frequencies

\begin{tabular}{|c|c|c|c|c|c|c|c|c|}
\hline 5 & 0 & 0 & 0 & 0 & 0 & 5 & 46 & 41 \\
\hline 4 & 0 & 0 & 0 & 0 & 0 & 1 & 1 & 2 \\
\hline 3 & 0 & 0 & 0 & 0 & 0 & 0 & 3 & 1 \\
\hline 2 & 0 & 0 & 0 & 0 & 0 & 0 & 1 & 1 \\
\hline 1 & 0 & 0 & 0 & 0 & 0 & 0 & 0 & 1 \\
\hline
\end{tabular}

\begin{tabular}{|l|c|c|c|c|c|c|c|c|}
\multicolumn{1}{c|}{} & \multicolumn{1}{c|}{ Year } \\
\cline { 2 - 9 } \multicolumn{1}{c|}{} & 1995 & 1996 & 1997 & 1998 & 1999 & 2000 & 2001 & 2002 \\
\hline Number of SND Outstanding & 1 & 1 & 1 & 3 & 3 & 3 & 3 & 3 \\
\hline Percentage of SND with Generic Pricing & 1 & 1 & 1 & 1 & 2 & 1 & 2 & 2 \\
\hline
\end{tabular}

\begin{tabular}{|l|c|c|c|c|c|c|c|c|}
\hline Number of Bond-Weeks & 52 & 52 & 52 & 110 & 156 & 156 & 156 & 150 \\
\hline Number of Bond-Weeks with Generic Pricing & 19 & 20 & 12 & 8 & 2 & 9 & 37 & 9 \\
\hline Percentage of Bond-Weeks with Generic Pricing & $36.54 \%$ & $38.46 \%$ & $23.08 \%$ & $7.27 \%$ & $1.28 \%$ & $5.77 \%$ & $23.72 \%$ & $6.00 \%$ \\
\hline
\end{tabular}

Number of Bond-Weeks with Various Frequencies

\begin{tabular}{|c|c|c|c|c|c|c|c|c|}
\hline 5 & 14 & 11 & 9 & 4 & 0 & 1 & 24 & 4 \\
\hline 4 & 1 & 2 & 3 & 2 & 0 & 0 & 6 & 1 \\
\hline 3 & 1 & 4 & 0 & 1 & 0 & 0 & 2 & 1 \\
\hline 2 & 1 & 2 & 0 & 4 & 2 & 1 & 3 & 2 \\
\hline 1 & 2 & 1 & 0 & 0 & 0 & 1 & 2 & 1 \\
\hline
\end{tabular}




\section{J.P. MORGAN CHASE \& CO (J.P. MORGAN) \\ RSSD $=1039502(1037115$ prior to $12 / 31 / 2000)$}

TICKER $=$ JPM

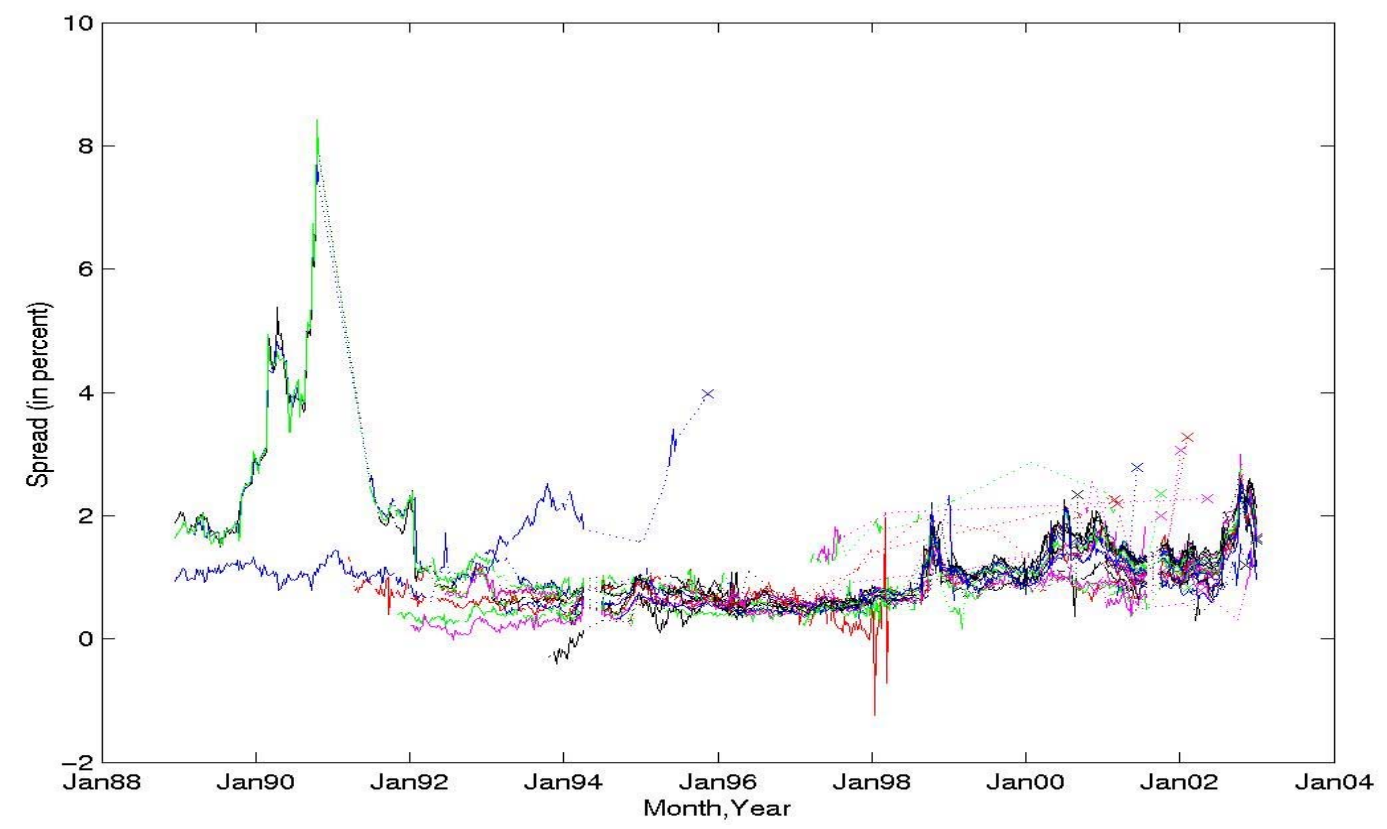

\begin{tabular}{|c|c|c|c|c|c|c|c|c|}
\hline & \multicolumn{8}{|c|}{ Year } \\
\hline & 1987 & 1988 & 1989 & 1990 & 1991 & 1992 & 1993 & 1994 \\
\hline Number of SND Outstanding & 2 & 4 & 5 & 5 & 8 & 12 & 15 & 19 \\
\hline Number of SND with Generic Pricing & 0 & 3 & 4 & 4 & 6 & 10 & 13 & 16 \\
\hline Percentage of SND with Generic Pricing & $0.00 \%$ & $75.00 \%$ & $80.00 \%$ & $80.00 \%$ & $75.00 \%$ & $83.33 \%$ & $86.67 \%$ & $84.21 \%$ \\
\hline Number of Bond-Weeks & 52 & 119 & 251 & 260 & 331 & 579 & 733 & 902 \\
\hline Number of Bond-Weeks with Generic Pricing & 0 & 9 & 199 & 180 & 166 & 388 & 540 & 416 \\
\hline Percentage of Bond-Weeks with Generic Pricing & $0.00 \%$ & $7.56 \%$ & $79.28 \%$ & $69.23 \%$ & $50.15 \%$ & $67.01 \%$ & $73.67 \%$ & $46.12 \%$ \\
\hline
\end{tabular}

Number of Bond-Weeks with Various Frequencies

\begin{tabular}{|c|c|c|c|c|c|c|c|c|}
\hline 5 & 0 & 6 & 175 & 166 & 71 & 293 & 441 & 326 \\
\hline 4 & 0 & 3 & 20 & 8 & 41 & 38 & 32 & 38 \\
\hline 3 & 0 & 0 & 1 & 0 & 30 & 20 & 28 & 17 \\
\hline 2 & 0 & 0 & 2 & 4 & 14 & 17 & 19 & 14 \\
\hline 1 & 0 & 0 & 1 & 2 & 10 & 20 & 20 & 21 \\
\hline
\end{tabular}

\begin{tabular}{|l|c|c|c|c|c|c|c|c|c|}
\multicolumn{1}{c|}{} & \multicolumn{9}{c|}{ Year } \\
\cline { 2 - 9 } \multicolumn{1}{c|}{} & 1995 & 1996 & 1997 & 1998 & 1999 & 2000 & 2001 & 2002 \\
\hline Number of SND Outstanding & 22 & 26 & 38 & 39 & 37 & 85 & 82 & 80 \\
\hline Percentage SND with Generic Pricing & 18 & 19 & 25 & 23 & 21 & 42 & 41 & 35 \\
\hline
\end{tabular}

\begin{tabular}{|l|c|c|c|c|c|c|c|c|}
\hline Number of Bond-Weeks & 992 & 1313 & 1711 & 1960 & 1855 & 1892 & 4195 & 3676 \\
\hline Number of Bond-Weeks with Generic Pricing & 619 & 672 & 778 & 661 & 595 & 500 & 1284 & 1159 \\
\hline Percentage of Bond-Weeks with Generic Pricing & $62.40 \%$ & $51.18 \%$ & $45.47 \%$ & $33.72 \%$ & $32.08 \%$ & $26.43 \%$ & $30.61 \%$ & $31.53 \%$ \\
\hline
\end{tabular}

Number of Bond-Weeks with Various Frequencies

\begin{tabular}{|c|c|c|c|c|c|c|c|c|}
\hline 5 & 504 & 494 & 582 & 452 & 473 & 422 & 1119 & 911 \\
\hline 4 & 43 & 59 & 67 & 65 & 54 & 14 & 51 & 82 \\
\hline 3 & 26 & 54 & 49 & 59 & 36 & 19 & 32 & 29 \\
\hline 2 & 29 & 30 & 36 & 38 & 17 & 14 & 29 & 65 \\
\hline 1 & 17 & 35 & 44 & 47 & 15 & 31 & 53 & 72 \\
\hline
\end{tabular}

*** Acquired Chase Manhattan Corporation on 12/31/2000 
SOCIETY CORP (KEYCORP)

$\mathrm{RSSD}=1068025$

TICKER $=$ KEY

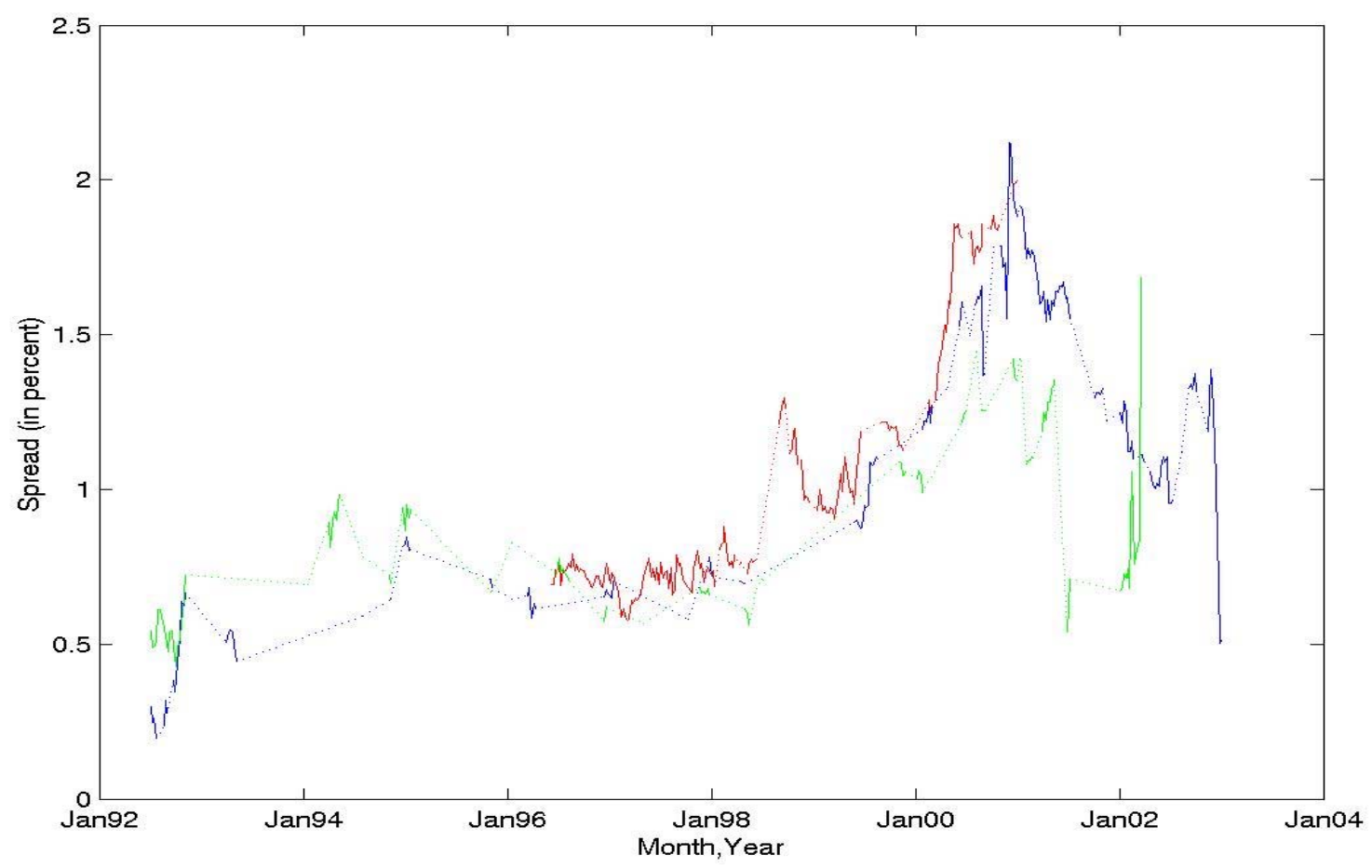

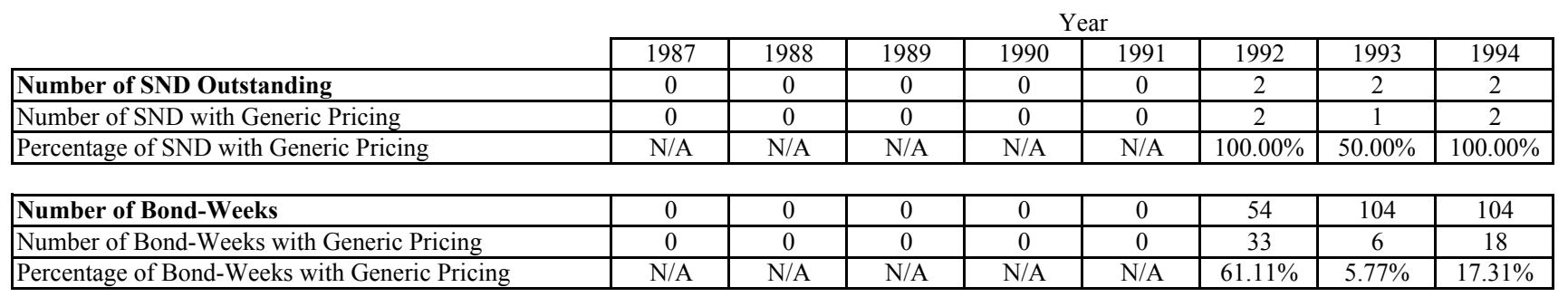

Number of Bond-Weeks with Various Frequencies

\begin{tabular}{|c|c|c|c|c|c|c|c|c|}
\hline 5 & N/A & N/A & N/A & N/A & N/A & 25 & 6 & 11 \\
\hline 4 & N/A & N/A & N/A & N/A & N/A & 3 & 0 & 0 \\
\hline 3 & N/A & N/A & N/A & N/A & N/A & 0 & 0 & 2 \\
\hline 2 & N/A & N/A & N/A & N/A & N/A & 3 & 0 & 2 \\
\hline 1 & N/A & N/A & N/A & N/A & N/A & 2 & 0 & 3 \\
\hline
\end{tabular}

\begin{tabular}{|l|c|c|c|c|c|c|c|c|}
\multicolumn{1}{c|}{} & \multicolumn{1}{c|}{ Year } \\
\cline { 2 - 9 } \multicolumn{1}{c|}{} & 1995 & 1996 & 1997 & 1998 & 1999 & 2000 & 2001 & 2002 \\
\hline Number of SND Outstanding & 2 & 4 & 4 & 5 & 6 & 6 & 6 & 6 \\
\hline Percentage of SND with Generic Pricing & 2 & 3 & 3 & 3 & 3 & 3 & 2 & 2 \\
\hline
\end{tabular}

\begin{tabular}{|l|c|c|c|c|c|c|c|c|}
\hline Number of Bond-Weeks & 104 & 178 & 208 & 237 & 303 & 312 & 312 & 284 \\
\hline Number of Bond-Weeks with Generic Pricing & 10 & 51 & 64 & 45 & 52 & 70 & 49 & 51 \\
\hline Percentage of Bond-Weeks with Generic Pricing & $9.62 \%$ & $28.65 \%$ & $30.77 \%$ & $18.99 \%$ & $17.16 \%$ & $22.44 \%$ & $15.71 \%$ & $17.96 \%$ \\
\hline
\end{tabular}

Number of Bond-Weeks with Various Frequencies

\begin{tabular}{|c|c|c|c|c|c|c|c|c|}
\hline 5 & 7 & 42 & 52 & 21 & 35 & 42 & 36 & 30 \\
\hline 4 & 0 & 1 & 5 & 6 & 7 & 8 & 2 & 7 \\
\hline 3 & 2 & 2 & 3 & 8 & 5 & 4 & 4 & 4 \\
\hline 2 & 0 & 3 & 3 & 5 & 3 & 9 & 3 & 7 \\
\hline 1 & 1 & 3 & 1 & 5 & 2 & 7 & 4 & 3 \\
\hline
\end{tabular}




\section{MELLON FINANCIAL CORP \\ RSSD $=1068762$ \\ TICKER $=$ MEL}

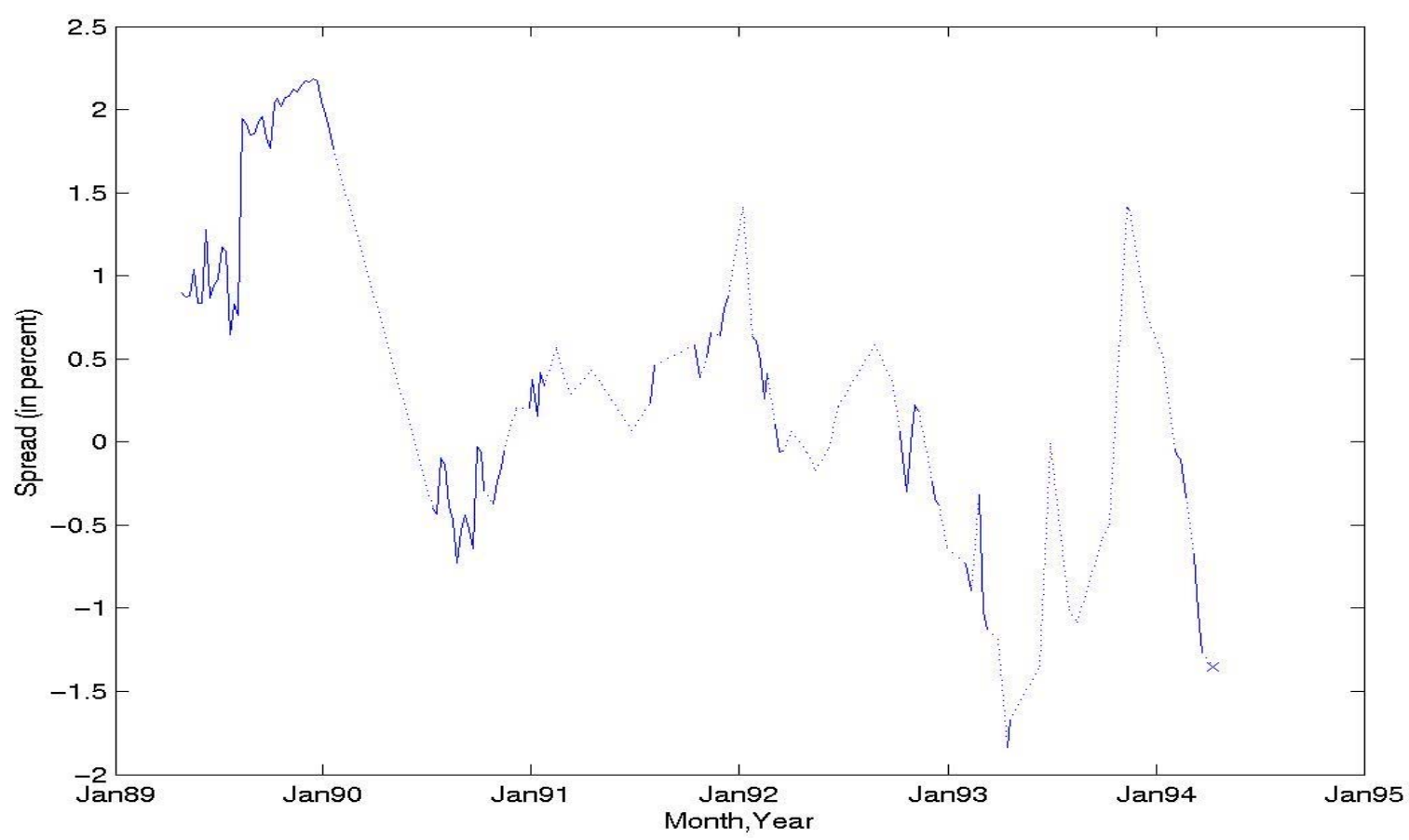

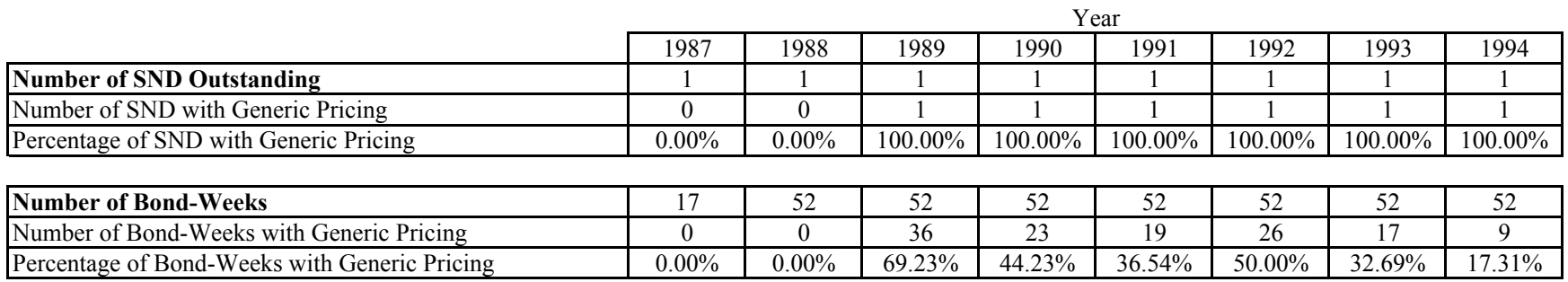

Number of Bond-Weeks with Various Frequencies

\begin{tabular}{|c|c|c|c|c|c|c|c|c|}
\hline 5 & 0 & 0 & 33 & 16 & 1 & 2 & 0 & 0 \\
\hline 4 & 0 & 0 & 2 & 2 & 0 & 1 & 0 & 0 \\
\hline 3 & 0 & 0 & 0 & 1 & 0 & 1 & 0 & 0 \\
\hline 2 & 0 & 0 & 1 & 1 & 4 & 7 & 2 & 0 \\
\hline 1 & 0 & 0 & 0 & 3 & 14 & 15 & 15 & 9 \\
\hline
\end{tabular}

\begin{tabular}{|c|c|c|c|c|c|c|c|c|}
\hline & \multicolumn{8}{|c|}{ Year } \\
\hline & 1995 & 1996 & 1997 & 1998 & 1999 & 2000 & 2001 & 2002 \\
\hline Number of SND Outstanding & 1 & 1 & 1 & 1 & 1 & 0 & 0 & 0 \\
\hline Number of SND with Generic Pricing & 0 & 0 & 0 & 0 & 0 & 0 & 0 & 0 \\
\hline Percentage of SND with Generic Pricing & $0.00 \%$ & $0.00 \%$ & $0.00 \%$ & $0.00 \%$ & $0.00 \%$ & $\mathrm{~N} / \mathrm{A}$ & $\mathrm{N} / \mathrm{A}$ & $\mathrm{N} / \mathrm{A}$ \\
\hline
\end{tabular}

\begin{tabular}{|l|c|c|c|c|c|c|c|c|}
\hline Number of Bond-Weeks & 52 & 52 & 52 & 52 & 36 & 0 & 0 & 0 \\
\hline Number of Bond-Weeks with Generic Pricing & 0 & 0 & 0 & 0 & 0 & 0 & 0 & 0 \\
\hline Percentage of Bond-Weeks with Generic Pricing & $0.00 \%$ & $0.00 \%$ & $0.00 \%$ & $0.00 \%$ & $0.00 \%$ & N/A & N/A & N/A \\
\hline
\end{tabular}

Number of Bond-Weeks with Various Frequencies

Number of Bond-Weeks with Various Frequencies
\begin{tabular}{|c|c|c|c|c|c|c|c|c|}
\hline 5 & 0 & 0 & 0 & 0 & 0 & 0 & 0 & 0 \\
\hline 4 & 0 & 0 & 0 & 0 & 0 & 0 & 0 & 0 \\
\hline 3 & 0 & 0 & 0 & 0 & 0 & 0 & 0 & 0 \\
\hline 2 & 0 & 0 & 0 & 0 & 0 & 0 & 0 & 0 \\
\hline 1 & 0 & 0 & 0 & 0 & 0 & 0 & 0 & 0 \\
\hline
\end{tabular}


REGIONS FINANCIAL CORP.

RSSD $=1078332$

TICKER $=$ RGBK

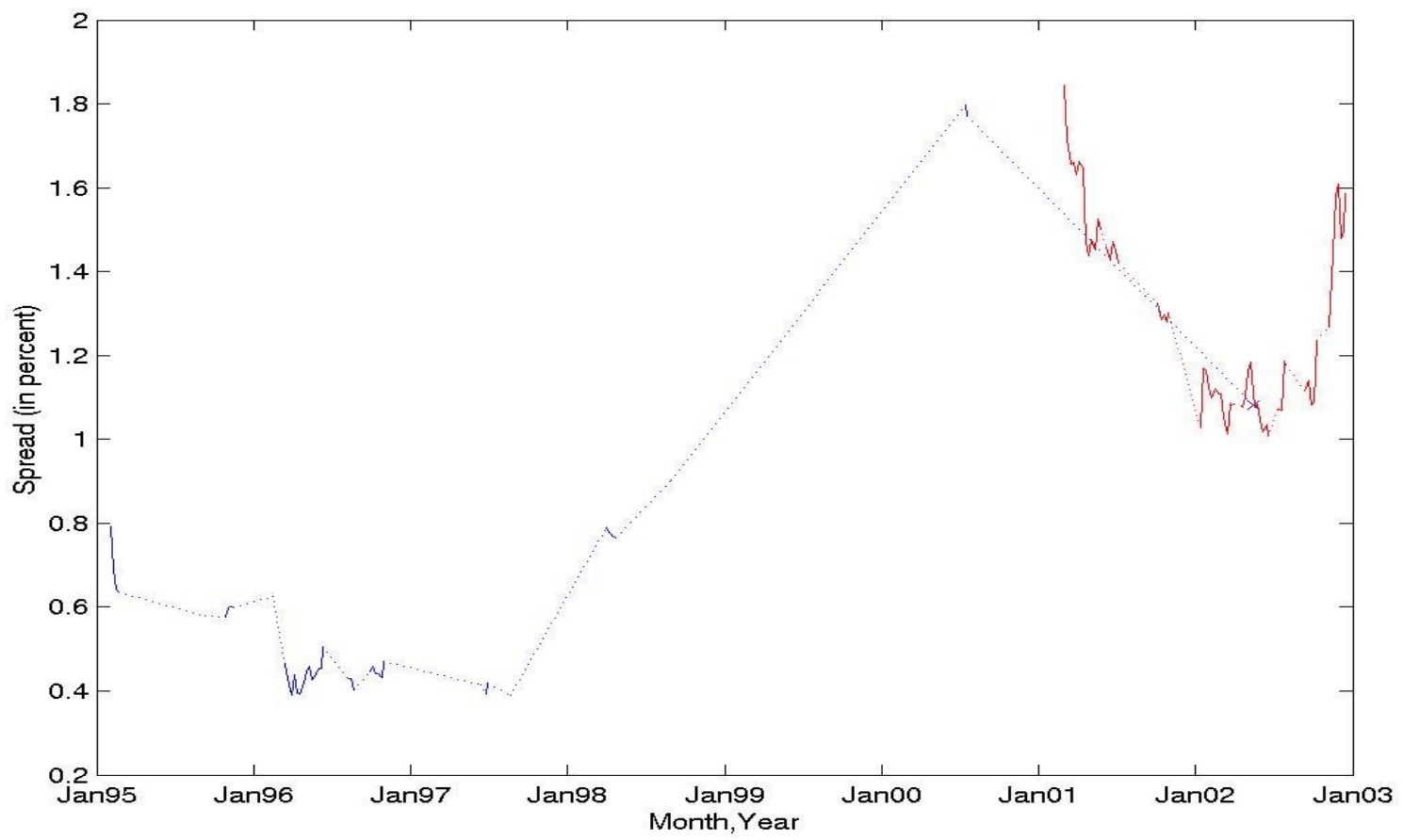

\begin{tabular}{|l|c|c|c|c|c|c|c|c|}
\multicolumn{1}{c|}{ Year } \\
\cline { 2 - 9 } \multicolumn{1}{c|}{} & 1987 & 1988 & 1989 & 1990 & 1991 & 1992 & 1993 & 1994 \\
\hline Number of SND Outstanding & 0 & 0 & 0 & 0 & 0 & 1 & 1 & 2 \\
\hline Percentage of SND with Generic Pricing & 0 & 0 & 0 & 0 & 0 & 0 & 0 & 0 \\
\hline
\end{tabular}

\begin{tabular}{|l|c|c|c|c|c|c|c|c|}
\hline Number of Bond-Weeks & 0 & 0 & 0 & 0 & 0 & 5 & 52 & 69 \\
\hline Number of Bond-Weeks with Generic Pricing & 0 & 0 & 0 & 0 & 0 & 0 & 0 & 0 \\
\hline Percentage of Bond-Weeks with Generic Pricing & N/A & N/A & N/A & N/A & N/A & $0.00 \%$ & $0.00 \%$ & $0.00 \%$ \\
\hline
\end{tabular}

Number of Bond-Weeks with Various Frequencies

\begin{tabular}{|c|c|c|c|c|c|c|c|c|}
\hline 5 & N/A & N/A & N/A & N/A & N/A & 0 & 0 & 0 \\
\hline 4 & N/A & N/A & N/A & N/A & N/A & 0 & 0 & 0 \\
\hline 3 & N/A & N/A & N/A & N/A & N/A & 0 & 0 & 0 \\
\hline 2 & N/A & N/A & N/A & N/A & N/A & 0 & 0 & 0 \\
\hline 1 & N/A & N/A & N/A & N/A & N/A & 0 & 0 & 0 \\
\hline
\end{tabular}

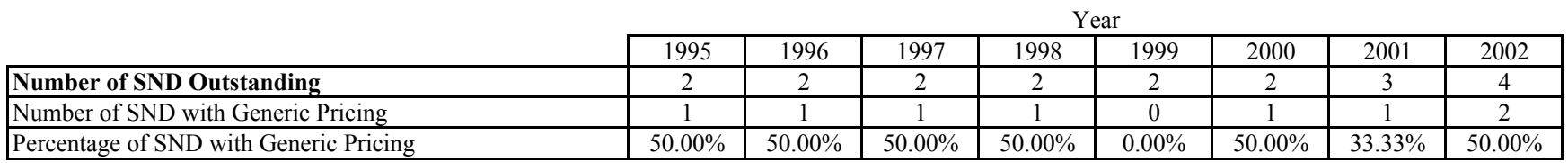

\begin{tabular}{|l|c|c|c|c|c|c|c|c|}
\hline Number of Bond-Weeks & 104 & 104 & 104 & 104 & 104 & 104 & 148 & 187 \\
\hline Number of Bond-Weeks with Generic Pricing & 9 & 24 & 4 & 5 & 0 & 2 & 23 & 40 \\
\hline Percentage of Bond-Weeks with Generic Pricing & $8.65 \%$ & $23.08 \%$ & $3.85 \%$ & $4.81 \%$ & $0.00 \%$ & $1.92 \%$ & $15.54 \%$ & $21.39 \%$ \\
\hline
\end{tabular}

\section{Number of Bond-Weeks with Various Frequencies}

\begin{tabular}{|c|c|c|c|c|c|c|c|c|}
\hline 5 & 3 & 13 & 0 & 3 & 0 & 0 & 19 & 27 \\
\hline 4 & 0 & 3 & 0 & 0 & 0 & 0 & 0 & 4 \\
\hline 3 & 3 & 3 & 1 & 0 & 0 & 1 & 3 & 3 \\
\hline 2 & 1 & 3 & 1 & 1 & 0 & 0 & 1 & 2 \\
\hline 1 & 2 & 2 & 2 & 1 & 0 & 1 & 0 & 4 \\
\hline
\end{tabular}




\section{REPUBLIC NEW YORK CORP.}

$\operatorname{RSSD}=1021075$

TICKER $=$ RNB

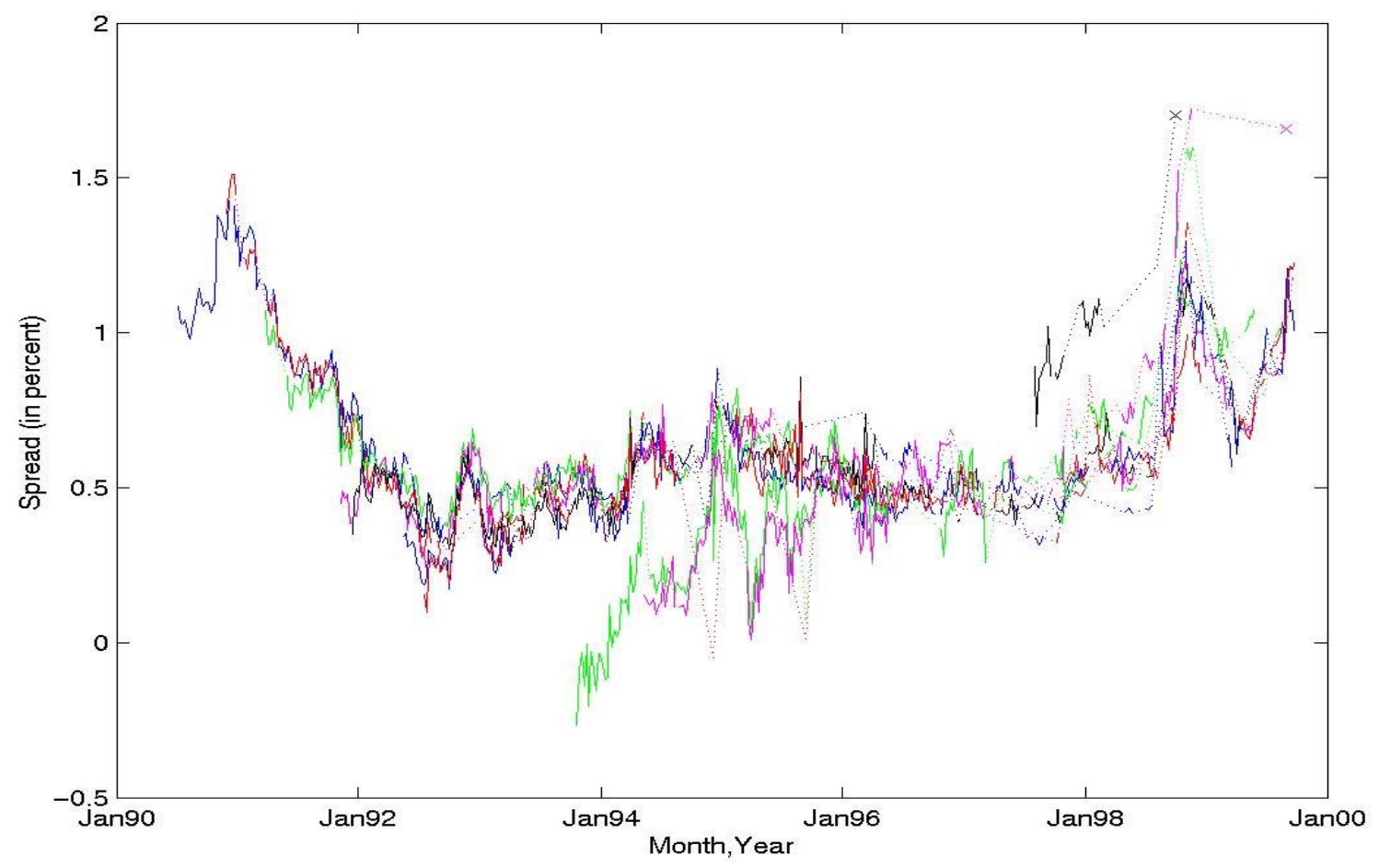

\begin{tabular}{|c|c|c|c|c|c|c|c|c|}
\hline & \multicolumn{8}{|c|}{ Year } \\
\hline & 1987 & 1988 & 1989 & 1990 & 1991 & 1992 & 1993 & 1994 \\
\hline \begin{tabular}{|l} 
Number of SND Outstanding \\
\end{tabular} & 0 & 0 & 2 & 4 & 9 & 14 & 15 & 16 \\
\hline Number of SND with Generic Pricing & 0 & 0 & 0 & 2 & 5 & 7 & 8 & 9 \\
\hline Percentage of SND with Generic Pricing & $\mathrm{N} / \mathrm{A}$ & $\mathrm{N} / \mathrm{A}$ & $0.00 \%$ & $50.00 \%$ & $55.56 \%$ & $50.00 \%$ & $53.33 \%$ & $56.25 \%$ \\
\hline Number of Bond-Weeks & 0 & 0 & 86 & 136 & 333 & 562 & 740 & 815 \\
\hline Number of Bond-Weeks with Generic Pricing & 0 & 0 & 0 & 30 & 145 & 268 & 288 & 297 \\
\hline Percentage of Bond-Weeks with Generic Pricing & $\mathrm{N} / \mathrm{A}$ & $\mathrm{N} / \mathrm{A}$ & $0.00 \%$ & $22.06 \%$ & $43.54 \%$ & $47.69 \%$ & $38.92 \%$ & $36.44 \%$ \\
\hline
\end{tabular}

Number of Bond-Weeks with Various Frequencies

\begin{tabular}{|c|c|c|c|c|c|c|c|c|}
\hline 5 & N/A & N/A & N/A & 22 & 95 & 200 & 214 & 218 \\
\hline 4 & N/A & N/A & N/A & 3 & 21 & 32 & 21 & 24 \\
\hline 3 & N/A & N/A & N/A & 2 & 18 & 19 & 22 & 15 \\
\hline 2 & N/A & N/A & N/A & 2 & 7 & 11 & 15 & 23 \\
\hline 1 & N/A & N/A & N/A & 1 & 4 & 6 & 16 & 17 \\
\hline
\end{tabular}

\begin{tabular}{|l|c|c|c|c|c|c|c|c|}
\multicolumn{1}{c|}{} & \multicolumn{1}{c|}{ Year } \\
\cline { 2 - 9 } \multicolumn{1}{c|}{} & 1995 & 1996 & 1997 & 1998 & 1999 & 2000 & 2001 & 2002 \\
\hline Number of SND Outstanding & 16 & 17 & 18 & 18 & 18 & N/A & N/A & N/A \\
\hline Pumber of SND with Generic Pricing & 9 & 9 & 10 & 10 & 9 & N/A & N/A & N/A \\
\hline
\end{tabular}

\begin{tabular}{|l|c|c|c|c|c|c|c|c|}
\hline Number of Bond-Weeks & 832 & 874 & 908 & 936 & 936 & N/A & N/A & N/A \\
\hline Number of Bond-Weeks with Generic Pricing & 330 & 270 & 191 & 242 & 121 & N/A & N/A & N/A \\
\hline Percentage of Bond-Weeks with Generic Pricing & $39.66 \%$ & $30.89 \%$ & $21.04 \%$ & $25.85 \%$ & $12.93 \%$ & N/A & N/A & N/A \\
\hline
\end{tabular}

Number of Bond-Weeks with Various Frequencies

\begin{tabular}{|c|c|c|c|c|c|c|c|c|}
\hline 5 & 255 & 202 & 115 & 128 & 68 & N/A & N/A & N/A \\
\hline 4 & 28 & 27 & 20 & 35 & 15 & N/A & N/A & N/A \\
\hline 3 & 22 & 16 & 21 & 30 & 15 & N/A & N/A & N/A \\
\hline 2 & 11 & 11 & 18 & 31 & 8 & N/A & N/A & N/A \\
\hline 1 & 14 & 14 & 17 & 18 & 15 & N/A & N/A & N/A \\
\hline
\end{tabular}




\section{SOUTHTRUST CORPORATION \\ RSSD $=1079441$ \\ TICKER $=$ SOTR}

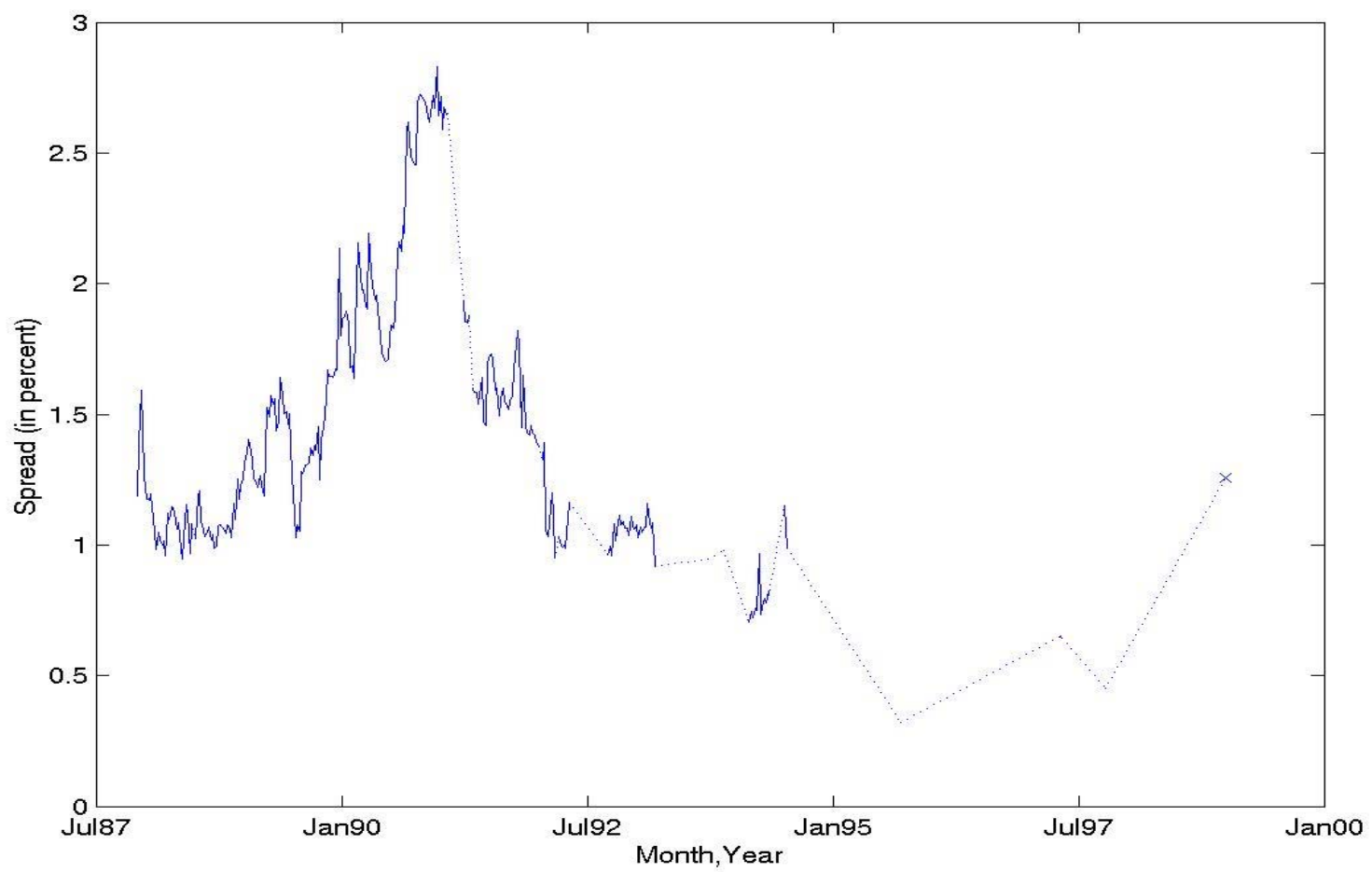

\begin{tabular}{|c|c|c|c|c|c|c|c|c|}
\hline & \multicolumn{8}{|c|}{ Year } \\
\hline & 1987 & 1988 & 1989 & 1990 & 1991 & 1992 & 1993 & 1994 \\
\hline Number of SND Outstanding & 1 & 1 & 1 & 1 & 2 & 3 & 4 & 4 \\
\hline Number of SND with Generic Pricing & 1 & 1 & 1 & 1 & 1 & 1 & 1 & 1 \\
\hline Percentage of SND with Generic Pricing & $100.00 \%$ & $100.00 \%$ & $100.00 \%$ & $100.00 \%$ & $50.00 \%$ & $33.33 \%$ & $25.00 \%$ & $25.00 \%$ \\
\hline Number of Bond-Weeks & 32 & 52 & 52 & 52 & 53 & 86 & 137 & 192 \\
\hline Number of Bond-Weeks with Generic Pricing & 5 & 51 & 52 & 52 & 44 & 31 & 12 & 14 \\
\hline Percentage of Bond-Weeks with Generic Pricing & $15.63 \%$ & $98.08 \%$ & $100.00 \%$ & $100.00 \%$ & $83.02 \%$ & $36.05 \%$ & $8.76 \%$ & $7.29 \%$ \\
\hline
\end{tabular}

Number of Bond-Weeks with Various Frequencies

\begin{tabular}{|c|c|c|c|c|c|c|c|c|}
\hline 5 & 3 & 40 & 44 & 49 & 28 & 18 & 8 & 11 \\
\hline 4 & 2 & 11 & 6 & 3 & 6 & 8 & 0 & 0 \\
\hline 3 & 0 & 0 & 1 & 0 & 6 & 1 & 2 & 0 \\
\hline 2 & 0 & 0 & 1 & 0 & 1 & 3 & 0 & 2 \\
\hline 1 & 0 & 0 & 0 & 0 & 3 & 1 & 2 & 1 \\
\hline
\end{tabular}

\begin{tabular}{|l|c|c|c|c|c|c|c|c|}
\multicolumn{1}{c|}{} & \multicolumn{1}{c|}{ Year } \\
\cline { 2 - 9 } \multicolumn{1}{c|}{} & 1995 & 1996 & 1997 & 1998 & 1999 & 2000 & 2001 & 2002 \\
\hline Number of SND Outstanding & 4 & 4 & 4 & 4 & 4 & 3 & 3 & 3 \\
\hline Pumber of SND with Generic Pricing & 1 & 0 & 1 & 1 & 0 & 0 & 0 & 0 \\
\hline
\end{tabular}

\begin{tabular}{|l|c|c|c|c|c|c|c|c|}
\hline Number of Bond-Weeks & 208 & 208 & 208 & 208 & 179 & 156 & 156 & 156 \\
\hline Number of Bond-Weeks with Generic Pricing & 1 & 0 & 3 & 1 & 0 & 0 & 0 & 0 \\
\hline Percentage of Bond-Weeks with Generic Pricing & $0.48 \%$ & $0.00 \%$ & $1.44 \%$ & $0.48 \%$ & $0.00 \%$ & $0.00 \%$ & $0.00 \%$ & $0.00 \%$ \\
\hline
\end{tabular}

Number of Bond-Weeks with Various Frequencies

\begin{tabular}{|c|c|c|c|c|c|c|c|c|}
\hline 5 & 0 & N/A & 1 & 0 & N/A & N/A & N/A & N/A \\
\hline 4 & 0 & N/A & 1 & 0 & N/A & N/A & N/A & N/A \\
\hline 3 & 0 & N/A & 0 & 0 & N/A & N/A & N/A & N/A \\
\hline 2 & 0 & N/A & 0 & 0 & N/A & N/A & N/A & N/A \\
\hline 1 & 1 & N/A & 1 & 1 & N/A & N/A & N/A & N/A \\
\hline
\end{tabular}


SUNTRUST BANKS INC.

RSSD $=1131787$

TICKER $=$ STI

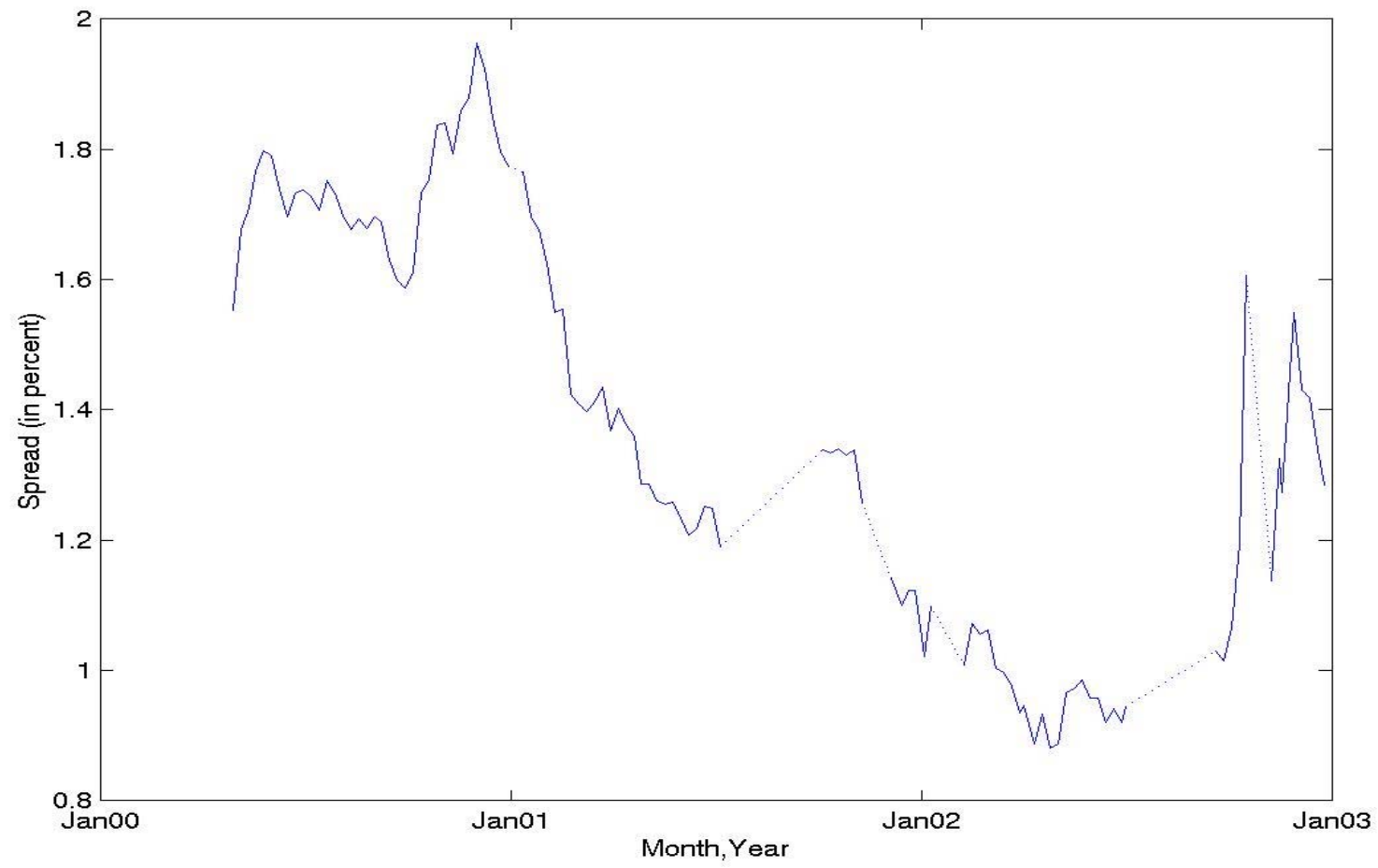

Number of SND with Generic Pricing

Percentage of SND with Generic Pricing

Year

\begin{tabular}{|l|c|c|c|c|c|c|c|c|}
\hline Number of Bond-Weeks & 0 & 0 & 0 & 0 & 0 & 0 & 0 & 48 \\
\hline Number of Bond-Weeks with Generic Pricing & 0 & 0 & 0 & 0 & 0 & 0 & 0 & 0 \\
\hline Percentage of Bond-Weeks with Generic Pricing & N/A & N/A & N/A & N/A & N/A & N/A & N/A & $0.00 \%$ \\
\hline
\end{tabular}

Number of Bond-Weeks with Various Frequencies

\begin{tabular}{|c|c|c|c|c|c|c|c|c|}
\hline 5 & N/A & N/A & N/A & N/A & N/A & N/A & N/A & 0 \\
\hline 4 & N/A & N/A & N/A & N/A & N/A & N/A & N/A & 0 \\
\hline 3 & N/A & N/A & N/A & N/A & N/A & N/A & N/A & 0 \\
\hline 2 & N/A & N/A & N/A & N/A & N/A & N/A & N/A & 0 \\
\hline 1 & N/A & N/A & N/A & N/A & N/A & N/A & N/A & 0 \\
\hline
\end{tabular}

\begin{tabular}{|l|c|c|c|c|c|c|c|c|}
\multicolumn{1}{c|}{} & \multicolumn{1}{c|}{ Year } \\
\cline { 2 - 9 } \multicolumn{1}{c|}{} & 1995 & 1996 & 1997 & 1998 & 1999 & 2000 & 2001 & 2002 \\
\hline Number of SND Outstanding & 1 & 3 & 4 & 4 & 4 & 5 & 5 & 5 \\
\hline Pumber of SND with Generic Pricing & 0 & 0 & 0 & 0 & 0 & 1 & 1 & 1 \\
\hline
\end{tabular}

\begin{tabular}{|l|c|c|c|c|c|c|c|c|}
\hline Number of Bond-Weeks & 52 & 125 & 189 & 208 & 208 & 244 & 260 & 260 \\
\hline Number of Bond-Weeks with Generic Pricing & 0 & 0 & 0 & 0 & 0 & 36 & 36 & 37 \\
\hline Percentage of Bond-Weeks with Generic Pricing & $0.00 \%$ & $0.00 \%$ & $0.00 \%$ & $0.00 \%$ & $0.00 \%$ & $14.75 \%$ & $13.85 \%$ & $14.23 \%$ \\
\hline
\end{tabular}

Number of Bond-Weeks with Various Frequencies

\begin{tabular}{|c|c|c|c|c|c|c|c|c|}
\hline 5 & 0 & 0 & 0 & 0 & 0 & 35 & 33 & 25 \\
\hline 4 & 0 & 0 & 0 & 0 & 0 & 0 & 0 & 4 \\
\hline 3 & 0 & 0 & 0 & 0 & 0 & 1 & 1 & 2 \\
\hline 2 & 0 & 0 & 0 & 0 & 0 & 0 & 0 & 3 \\
\hline 1 & 0 & 0 & 0 & 0 & 0 & 0 & 2 & 3 \\
\hline
\end{tabular}




\section{UNION PLANTERS}

RSSD $=1094369$

TICKER $=$ UPC

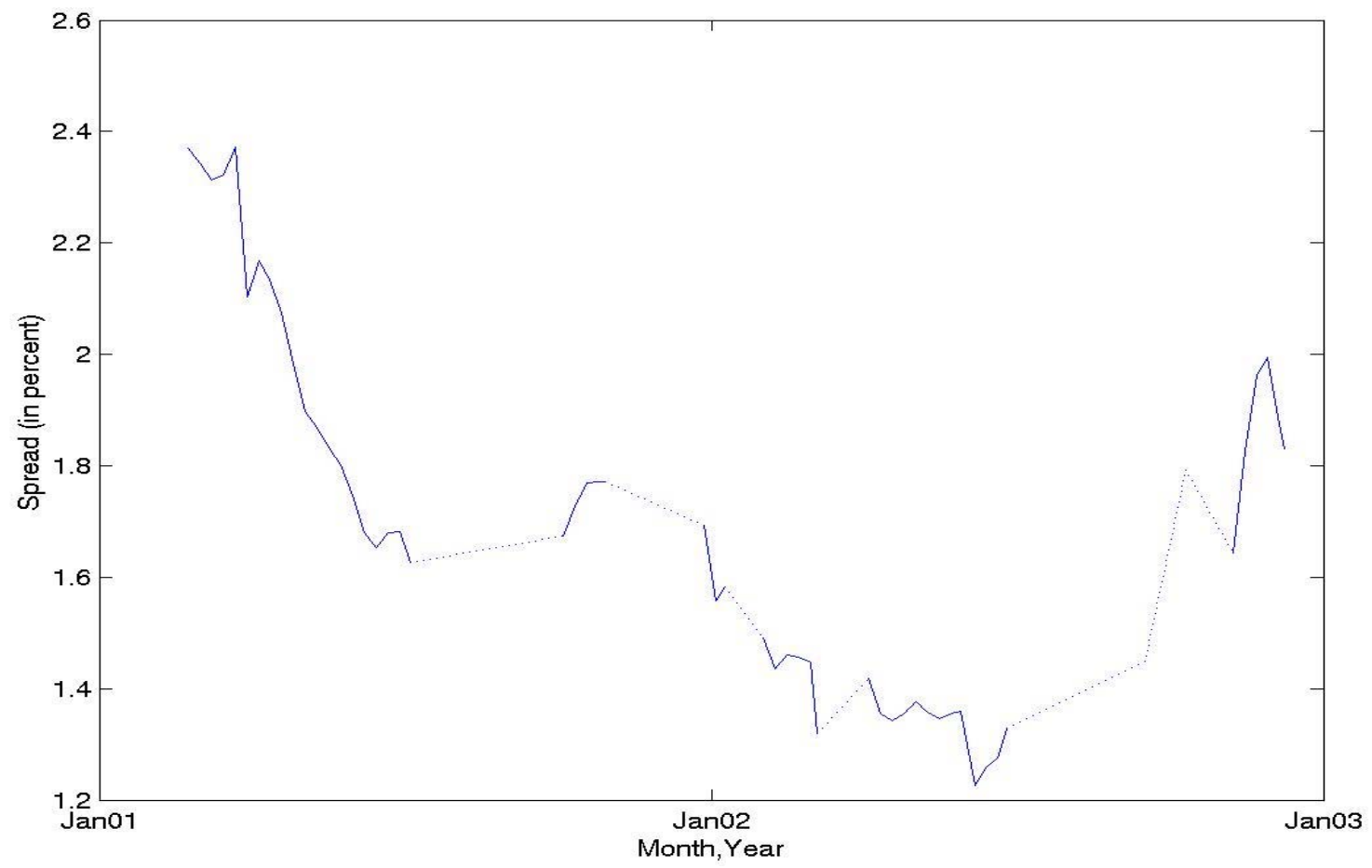

\begin{tabular}{|l|c|c|c|c|c|c|c|c|}
\multicolumn{1}{c|}{} & \multicolumn{1}{c}{ Year } \\
\cline { 2 - 9 } \multicolumn{1}{c|}{} & 1987 & 1988 & 1989 & 1990 & 1991 & 1992 & 1993 & 1994 \\
\hline Number of SND Outstanding & 0 & 0 & 0 & 0 & 0 & 0 & 1 & 1 \\
\hline Pumber of SND with Generic Pricing & 0 & 0 & 0 & 0 & 0 & 0 & 0 & 0 \\
\hline
\end{tabular}

\begin{tabular}{|l|c|c|c|c|c|c|c|c|}
\hline Number of Bond-Weeks & 0 & 0 & 0 & 0 & 0 & 0 & 10 & 52 \\
\hline Number of Bond-Weeks with Generic Pricing & 0 & 0 & 0 & 0 & 0 & 0 & 0 & 0 \\
\hline Percentage of Bond-Weeks with Generic Pricing & N/A & N/A & N/A & N/A & N/A & N/A & N/A & N/A \\
\hline
\end{tabular}

Number of Bond-Weeks with Various Frequencies

\begin{tabular}{|c|c|c|c|c|c|c|c|c|}
\hline 5 & N/A & N/A & N/A & N/A & N/A & N/A & 0 & 0 \\
\hline 4 & N/A & N/A & N/A & N/A & N/A & N/A & 0 & 0 \\
\hline 3 & N/A & N/A & N/A & N/A & N/A & N/A & 0 & 0 \\
\hline 2 & N/A & N/A & N/A & N/A & N/A & N/A & 0 & 0 \\
\hline 1 & $\mathrm{~N} / \mathrm{A}$ & $\mathrm{N} / \mathrm{A}$ & N/A & N/A & $\mathrm{N} / \mathrm{A}$ & $\mathrm{N} / \mathrm{A}$ & 0 & 0 \\
\hline
\end{tabular}

\begin{tabular}{|l|c|c|c|c|c|c|c|c|}
\multicolumn{1}{c|}{ Year } \\
\cline { 2 - 9 } \multicolumn{1}{c|}{} & 1995 & 1996 & 1997 & 1998 & 1999 & 2000 & 2001 & 2002 \\
\hline Number of SND Outstanding & 2 & 2 & 2 & 2 & 2 & 2 & 3 & 3 \\
\hline Pumber of SND with Generic Pricing & 0 & 0 & 0 & 0 & 0 & 0 & 1 & 1 \\
\hline
\end{tabular}

\begin{tabular}{|l|c|c|c|c|c|c|c|c|}
\hline Number of Bond-Weeks & 61 & 104 & 104 & 104 & 104 & 104 & 149 & 156 \\
\hline Number of Bond-Weeks with Generic Pricing & 0 & 0 & 0 & 0 & 0 & 0 & 26 & 29 \\
\hline Percentage of Bond-Weeks with Generic Pricing & $0.00 \%$ & $0.00 \%$ & $0.00 \%$ & $0.00 \%$ & $0.00 \%$ & $0.00 \%$ & $17.45 \%$ & $18.59 \%$ \\
\hline
\end{tabular}

\section{Number of Bond-Weeks with Various Frequencies}

\begin{tabular}{|c|c|c|c|c|c|c|c|c|}
\hline 5 & 0 & 0 & 0 & 0 & 0 & 0 & 22 & 16 \\
\hline 4 & 0 & 0 & 0 & 0 & 0 & 0 & 1 & 3 \\
\hline 3 & 0 & 0 & 0 & 0 & 0 & 0 & 0 & 1 \\
\hline 2 & 0 & 0 & 0 & 0 & 0 & 0 & 1 & 3 \\
\hline 1 & 0 & 0 & 0 & 0 & 0 & 0 & 2 & 6 \\
\hline
\end{tabular}




\section{U.S. BANCORP}

RSSD $=1119794$ (previously 2724645 through 2001, 1070251 through 1998Q3)

TICKER $=$ USB

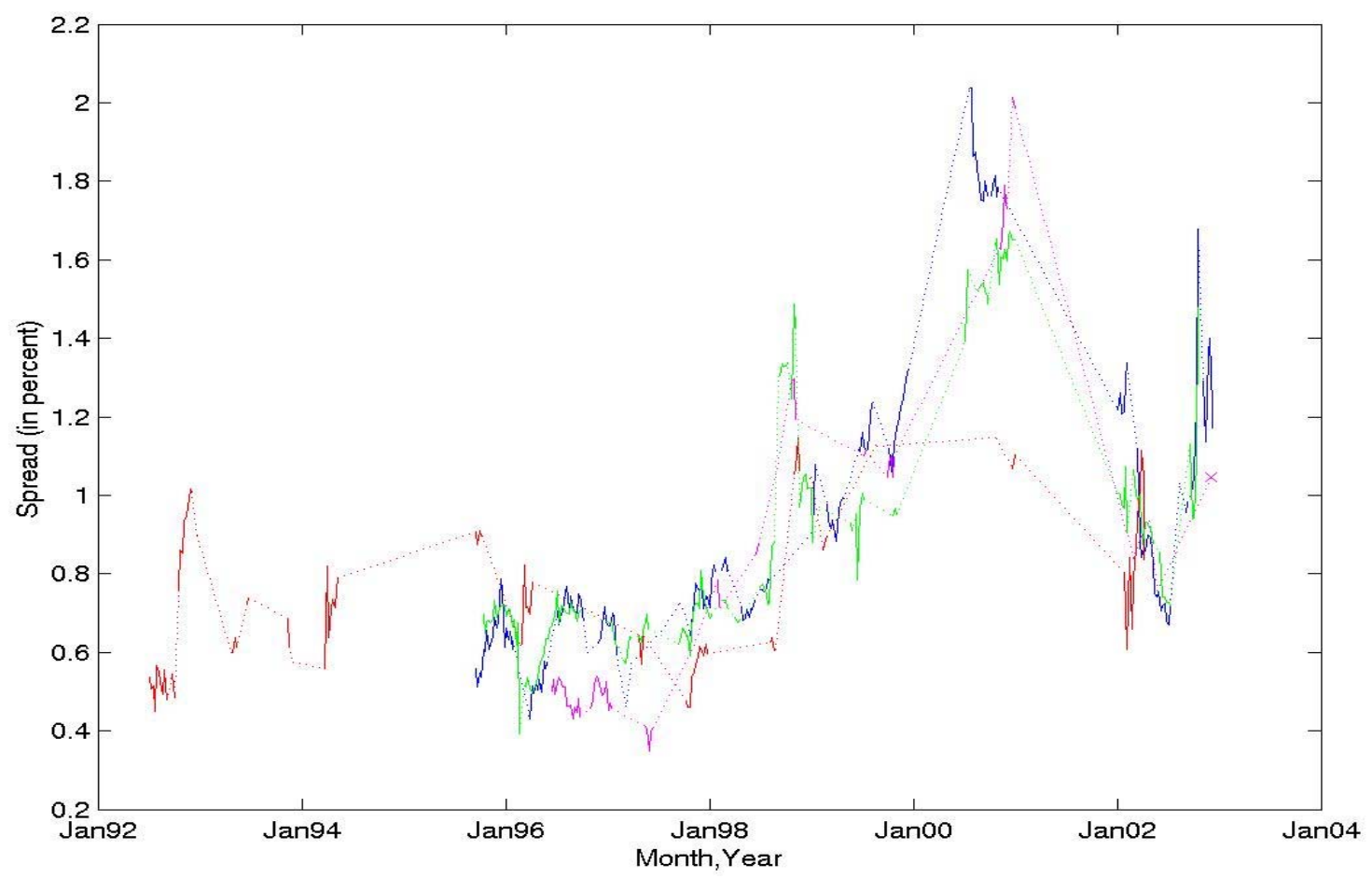

\begin{tabular}{|l|c|c|c|c|c|c|c|c|}
\multicolumn{1}{c|}{} & \multicolumn{1}{c|}{ Year } \\
\cline { 2 - 9 } \multicolumn{1}{c|}{} & 1987 & 1988 & 1989 & 1990 & 1991 & 1992 & 1993 & 1994 \\
\hline Number of SND Outstanding & 0 & 0 & 0 & 0 & 0 & 0 & 2 & 2 \\
\hline Pumber of SND with Generic Pricing & 0 & 0 & 0 & 0 & 0 & 0 & 1 & 1 \\
\hline
\end{tabular}

\begin{tabular}{|l|c|c|c|c|c|c|c|c|}
\hline Number of Bond-Weeks & 0 & 0 & 0 & 0 & 0 & 0 & 78 & 104 \\
\hline Number of Bond-Weeks with Generic Pricing & 0 & 0 & 0 & 0 & 0 & 0 & 9 & 8 \\
\hline Percentage of Bond-Weeks with Generic Pricing & N/A & N/A & N/A & N/A & N/A & N/A & $11.54 \%$ & $7.69 \%$ \\
\hline
\end{tabular}

\section{Number of Bond-Weeks with Various Frequencies}

\begin{tabular}{|c|c|c|c|c|c|c|c|c|}
\hline 5 & N/A & $\mathrm{N} / \mathrm{A}$ & N/A & N/A & N/A & N/A & 2 & 6 \\
\hline 4 & N/A & N/A & N/A & N/A & N/A & $\mathrm{N} / \mathrm{A}$ & 2 & 0 \\
\hline 3 & N/A & N/A & N/A & N/A & $\mathrm{N} / \mathrm{A}$ & N/A & 2 & 0 \\
\hline 2 & N/A & N/A & N/A & N/A & N/A & N/A & 0 & 1 \\
\hline 1 & $\mathrm{~N} / \mathrm{A}$ & $\mathrm{N} / \mathrm{A}$ & N/A & $\mathrm{N} / \mathrm{A}$ & $\mathrm{N} / \mathrm{A}$ & $\mathrm{N} / \mathrm{A}$ & 3 & 1 \\
\hline
\end{tabular}

\begin{tabular}{|l|c|c|c|c|c|c|c|c|}
\multicolumn{1}{c|}{} & \multicolumn{1}{c|}{ Year } \\
\cline { 2 - 10 } \multicolumn{1}{c|}{} & 1995 & 1996 & 1997 & 1998 & 1999 & 2000 & 2001 & 2002 \\
\hline Number of SND Outstanding & 5 & 6 & 6 & 6 & 6 & 6 & 6 & 6 \\
\hline Pumber of SND with Generic Pricing & 3 & 4 & 4 & 4 & 4 & 4 & 0 & 4 \\
\hline
\end{tabular}

\begin{tabular}{|l|c|c|c|c|c|c|c|c|}
\hline Number of Bond-Weeks & 170 & 289 & 312 & 312 & 312 & 312 & 312 & 312 \\
\hline Number of Bond-Weeks with Generic Pricing & 33 & 107 & 80 & 78 & 56 & 48 & 0 & 84 \\
\hline Percentage of Bond-Weeks with Generic Pricing & $19.41 \%$ & $37.02 \%$ & $25.64 \%$ & $25.00 \%$ & $17.95 \%$ & $15.38 \%$ & $0.00 \%$ & $26.92 \%$ \\
\hline
\end{tabular}

Number of Bond-Weeks with Various Frequencies

\begin{tabular}{|c|c|c|c|c|c|c|c|c|}
\hline 5 & 26 & 75 & 57 & 43 & 23 & 34 & N/A & 39 \\
\hline 4 & 2 & 11 & 7 & 12 & 7 & 5 & N/A & 14 \\
\hline 3 & 1 & 8 & 6 & 10 & 9 & 0 & N/A & 7 \\
\hline 2 & 2 & 5 & 2 & 7 & 12 & 4 & N/A & 9 \\
\hline 1 & 2 & 8 & 8 & 6 & 5 & 5 & N/A & 15 \\
\hline
\end{tabular}

** Acquired Firstar on 12/31/1998 
WACHOVIA

$\mathrm{RSSD}=1136157(1073551$ prior to $12 / 31 / 2001)$

TICKER $=\mathrm{WB}$

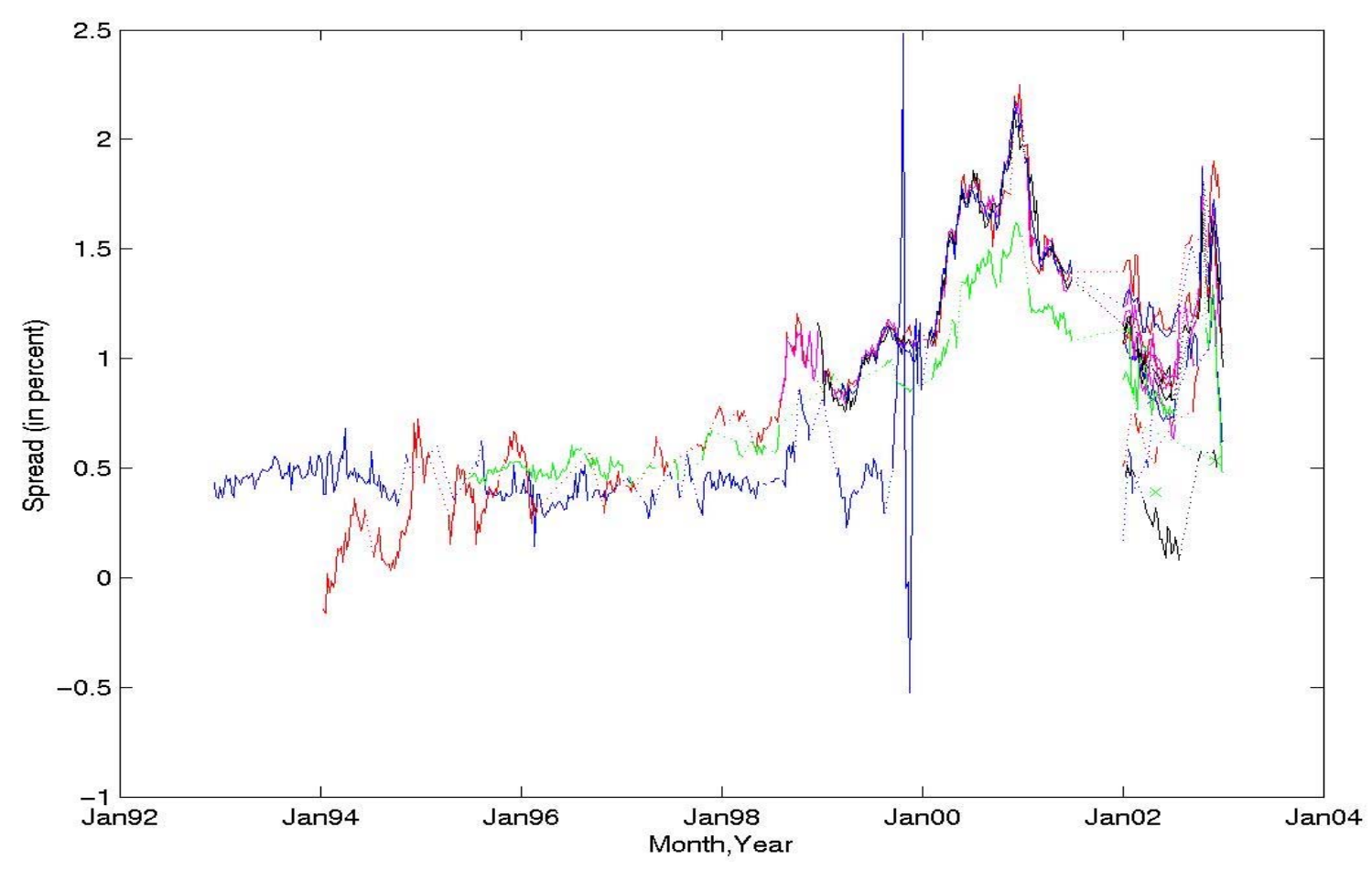

\begin{tabular}{|l|c|c|c|c|c|c|c|c|}
\multicolumn{1}{c|}{} & \multicolumn{1}{c|}{ Year } \\
\cline { 2 - 9 } \multicolumn{1}{c|}{} & 1987 & 1988 & 1989 & 1990 & 1991 & 1992 & 1993 & 1994 \\
\hline Number of SND Outstanding & 0 & 0 & 0 & 0 & 0 & 1 & 2 & 3 \\
\hline Pumber of SND with Generic Pricing & 0 & 0 & 0 & 0 & 0 & 1 & 1 & 2 \\
\hline
\end{tabular}

\begin{tabular}{|l|c|c|c|c|c|c|c|c|}
\hline Number of Bond-Weeks & 0 & 0 & 0 & 0 & 0 & 5 & 90 & 155 \\
\hline Number of Bond-Weeks with Generic Pricing & 0 & 0 & 0 & 0 & 0 & 4 & 52 & 93 \\
\hline Percentage of Bond-Weeks with Generic Pricing & N/A & N/A & N/A & N/A & N/A & $80.00 \%$ & $57.78 \%$ & $60.00 \%$ \\
\hline
\end{tabular}

Number of Bond-Weeks with Various Frequencies

Number of Bond-Weeks with Various Frequencies
\begin{tabular}{|c|c|c|c|c|c|c|c|c|}
\hline 5 & N/A & N/A & N/A & N/A & N/A & 3 & 45 & 74 \\
\hline 4 & N/A & N/A & N/A & N/A & N/A & 1 & 5 & 5 \\
\hline 3 & N/A & N/A & N/A & N/A & N/A & 0 & 2 & 8 \\
\hline 2 & N/A & N/A & N/A & N/A & N/A & 0 & 0 & 4 \\
\hline 1 & N/A & N/A & N/A & N/A & N/A & 0 & 0 & 2 \\
\hline
\end{tabular}

\begin{tabular}{|l|c|c|c|c|c|c|c|c|}
\multicolumn{1}{c|}{ Year } \\
\cline { 2 - 9 } \multicolumn{1}{c|}{} & 1995 & 1996 & 1997 & 1998 & 1999 & 2000 & 2001 & 2002 \\
\hline Number of SND Outstanding & 5 & 5 & 5 & 7 & 8 & 7 & 7 & 25 \\
\hline Pumber of SND with Generic Pricing & 3 & 3 & 3 & 5 & 6 & 5 & 5 & 15 \\
\hline
\end{tabular}

\begin{tabular}{|l|c|c|c|c|c|c|c|c|}
\hline Number of Bond-Weeks & 200 & 260 & 260 & 284 & 406 & 364 & 364 & 1268 \\
\hline Number of Bond-Weeks with Generic Pricing & 95 & 120 & 74 & 117 & 243 & 240 & 68 & 481 \\
\hline Percentage of Bond-Weeks with Generic Pricing & $47.50 \%$ & $46.15 \%$ & $28.46 \%$ & $41.20 \%$ & $59.85 \%$ & $65.93 \%$ & $18.68 \%$ & $37.93 \%$ \\
\hline
\end{tabular}

\section{Number of Bond-Weeks with Various Frequencies}

\begin{tabular}{|c|c|c|c|c|c|c|c|c|}
\hline 5 & 76 & 91 & 43 & 81 & 184 & 212 & 120 & 354 \\
\hline 4 & 6 & 15 & 4 & 10 & 27 & 14 & 1 & 40 \\
\hline 3 & 6 & 6 & 11 & 14 & 19 & 4 & 0 & 18 \\
\hline 2 & 6 & 6 & 6 & 6 & 13 & 4 & 0 & 23 \\
\hline 1 & 1 & 2 & 10 & 6 & 0 & 6 & 2 & 46 \\
\hline
\end{tabular}


WELLS FARGO \& CO.

$\mathrm{RSSD}=1120754(1027095$ prior to $10 / 01 / 1998)$

$\mathrm{TICKER}=\mathrm{WFC}$

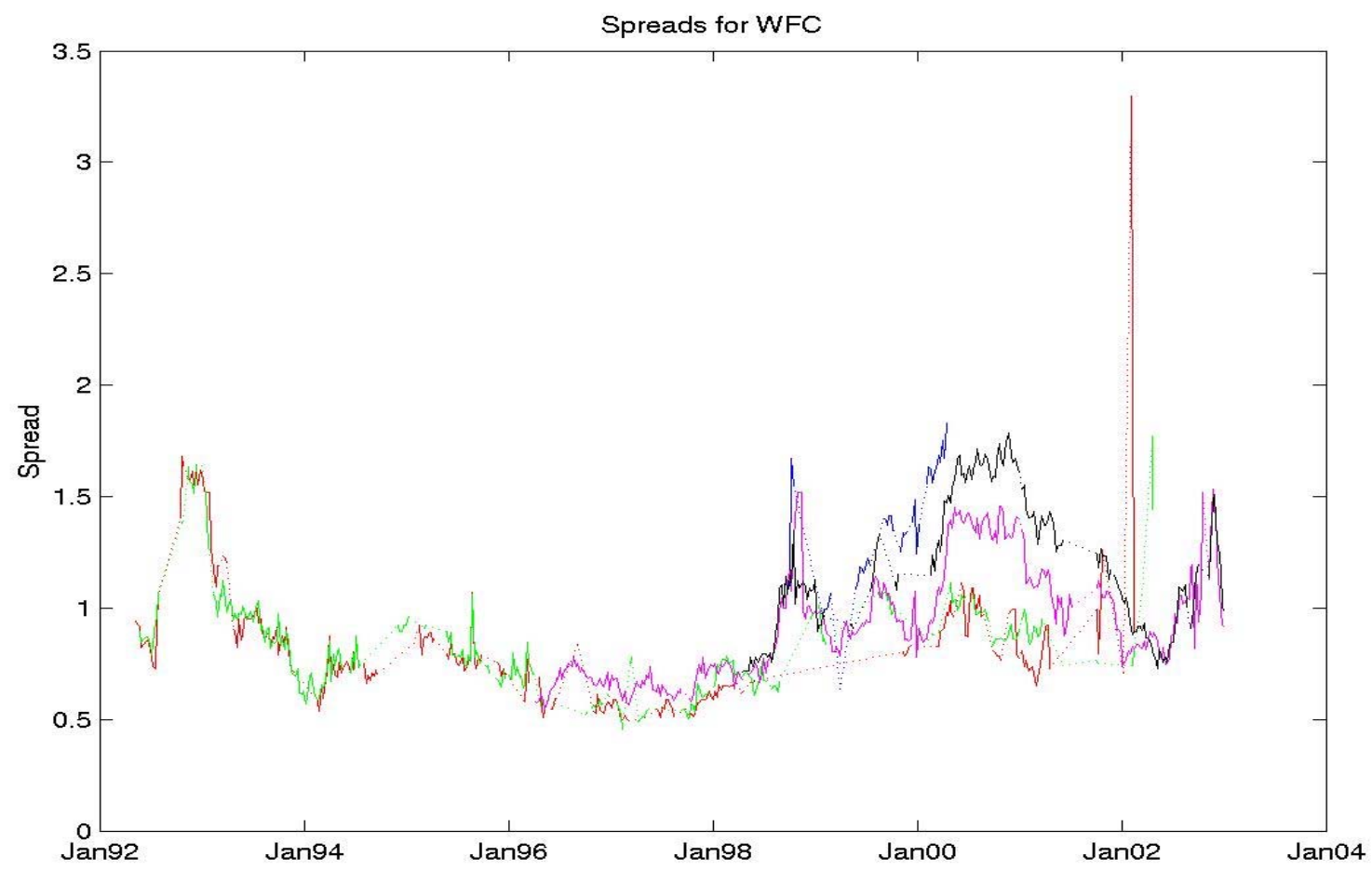

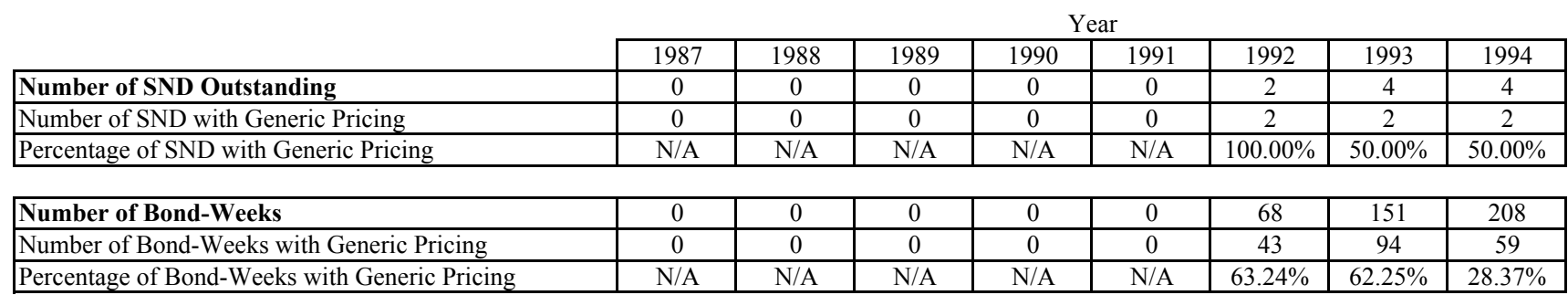

Number of Bond-Weeks with Various Frequencies

\begin{tabular}{|c|c|c|c|c|c|c|c|c|}
\hline 5 & N/A & N/A & N/A & N/A & N/A & 26 & 78 & 47 \\
\hline 4 & N/A & N/A & N/A & N/A & N/A & 6 & 3 & 7 \\
\hline 3 & N/A & N/A & N/A & N/A & N/A & 4 & 6 & 2 \\
\hline 2 & N/A & N/A & N/A & N/A & N/A & 3 & 4 & 2 \\
\hline 1 & N/A & N/A & N/A & N/A & N/A & 4 & 3 & 1 \\
\hline
\end{tabular}

\begin{tabular}{|l|c|c|c|c|c|c|c|c|}
\multicolumn{1}{c|}{} & \multicolumn{1}{c|}{ Year } \\
\cline { 2 - 9 } \multicolumn{1}{c|}{} & 1995 & 1996 & 1997 & 1998 & 1999 & 2000 & 2001 & 2002 \\
\hline Number of SND Outstanding & 4 & 6 & 6 & 7 & 7 & 7 & 8 & 11 \\
\hline Percentage of SND with Generic Pricing & 2 & 3 & 3 & 5 & 5 & 5 & 4 & 4 \\
\hline
\end{tabular}

\begin{tabular}{|l|c|c|c|c|c|c|c|c|}
\hline Number of Bond-Weeks & 208 & 269 & 312 & 349 & 364 & 364 & 387 & 394 \\
\hline Number of Bond-Weeks with Generic Pricing & 66 & 86 & 111 & 145 & 118 & 181 & 106 & 107 \\
\hline Percentage of Bond-Weeks with Generic Pricing & $31.73 \%$ & $31.97 \%$ & $35.58 \%$ & $41.55 \%$ & $32.42 \%$ & $49.73 \%$ & $27.39 \%$ & $27.16 \%$ \\
\hline
\end{tabular}

Number of Bond-Weeks with Various Frequencies

\begin{tabular}{|c|c|c|c|c|c|c|c|c|}
\hline 5 & 47 & 63 & 89 & 111 & 84 & 144 & 94 & 84 \\
\hline 4 & 5 & 9 & 7 & 14 & 11 & 14 & 2 & 5 \\
\hline 3 & 4 & 4 & 5 & 7 & 8 & 10 & 4 & 2 \\
\hline 2 & 7 & 4 & 3 & 6 & 9 & 5 & 2 & 7 \\
\hline 1 & 3 & 6 & 7 & 7 & 6 & 8 & 4 & 9 \\
\hline
\end{tabular}

